\title{
Al final del Imperio: El sitio arqueologico Inca-Caranqui en la Sierra Septentrional del Ecuador
}

Tamara L. Bray' y José Echeverría A. ${ }^{2}$

\begin{abstract}
RESUMEN
ESTE ARTíCULO INFORMA SOBRE LAS INVESTIGACIONES RECIENTES EN EL SITIO IMPERIAL TARDío INCA-CARANQUI

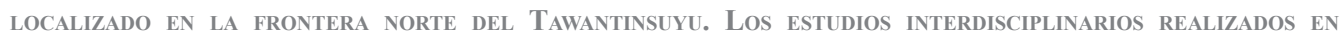
ESTE SITIO DESDE EL AÑO 2008 SE HAN DIRIGIDO A EXPLORAR EL PAPEL DE LA ARQUITECTURA IMPERIAL COMO UNA ESTRATEGIA MATERIAL DE LA POLÍTICA INCAICA Y EL TIPO O CLASES DE TÁCTICAS MILITARES Y SOCIALES QUE PUEDEN

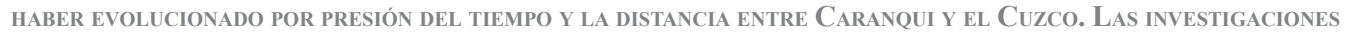
EN EL SITIO HAN IMPLICADO EL USO DE SENSORES REMOTOS DE RADAR (GPR), TÉCNICOS GEOQUímicos, EL USO EXPERIMENTAL DE LIDAR PARA LA REPRESENTACIÓN 3D, EXCAVACIONES CONTROLADAS Y ESTUDIOS ETNOHISTÓRICOS. UNA DESCRIPCIÓN Y ALGUNOS RESULTADOS PRELIMINARES DE ESTAS ACTIVIDADES SE PRESENTAN EN ESTE ARTÍCULO. LOS HALLAZGOS DISCUTIDOS AQUÚ INCLUYEN NUESTRA INTERPRETACIÓN DE LOS COMPONENTES ESTRUCTURALES DEL SITIO Y SU CONFIGURACIÓN, LOS MATERIALES Y TÉCNICAS DE CONSTRUCCIÓN, LOS CONTEXTOS FECHADOS Y EL SIGNIFICADO DE LA MANIPULACIÓN DEL AGUa EN EL SITIO.
\end{abstract}

Palabras Clave: Imperio Inca - Arquitectura hidraúlica Inca - Caranqui.

Abstract

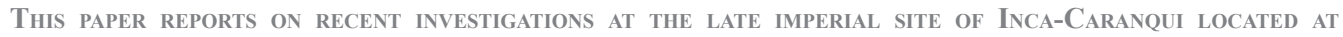
THE NORTHERNMOST EDGE OF TAWANTINSUYU. THE INTERDISCIPLINARY RESEARCH CONDUCTED AT THIS SITE SINCE 2008 HAS BEEN AIMED AT EXPLORING THE ROLE OF IMPERIAL ARCHITECTURE AS A MATERIAL STRATEGY OF INCA STATECRAFT AND THE EXTENT TO WHICH SUCH STRATEGIES MAY HAVE EVOLVED AS A FUNCTION OF TIME AND DISTANCE FROM tHE IMPERIAL CAPITAL OF CUZCO. INVESTIGATIONS AT THE SITE HAVE INVOLVED THE USE OF A VARIETY OF METHODOLOGICAL TECHNIQUES AS WELL AS CONTROLLED EXCAVATIONS, AND ETHNOHISTORIC RESEARCH. AN OVERVIEW OF THE ETHNOHISTORIC CONTEXT OF THE SITE TOGETHER WITH SOME OF THE PRELIMINARY RESULTS OF OUR FIELDWORK ARE PRESENTED IN THIS PAPER.

Key Words: Inca Empire - hydraulic Inca Architecture - Caranqui.

1 Tamara L. Bray, Profesora, Departmento de Antropología, Wayne State University, Detroit, Michigan, and 2014 Investigadora Prometeo con el GADM, Cantón Ibarra y Universidad Técnica del Norte, Ecuador t.bray@wayne.edu

2 José Echeverría Almeida, consultor independiente, Otavalo, Ecuador joecheve50@yahoo.com 
$\mathrm{L}$ a región circum-quiteña de la sierra ecuatorial fue la última área anexada por las fuerzas Incas antes de la invasión española. Las fuentes documentales tempranas generalmente están de acuerdo en que fue Topa Inga Yupanqui quien llevó a cabo las primeras entradas a la región, pero que recayó en su hijo, Huayna Capac, el establecer firmemente su control (Atienza 1931 [1575?]: 21; Betanzos, 1996 [1551-57]: 143; Cabello Balboa, 1951 [1586]: 321-330; Cieza de León, 1995 [1553]: 133). La frontera norte fue, de hecho, el principal foco de los esfuerzos militares durante las últimas décadas del Imperio Inca, consumiendo la mayor parte de la atención de Huayna Capac y sus recursos. De manera sorprendente sin embargo, discusiones sobre esta área son generalmente minimizadas o totalmente omitidas de la narrativa a gran escala sobre el Tawantinsuyu.

Como se ha hecho evidente gracias a algunos nuevos sitios y estudios en la región, (por ejemplo, Bray y Echeverría, 2009, 2010, 2011; Cruz, 2011; Estupiñán, 2011; González et al., 2009; Lippi y Gudiño, 2010; Ogburn et al., 2009; Rodríguez, 2011; Yépez, 2013), aún hay mucho que aprender respecto a los objetivos de la expansión Inca y la evolución de las prácticas imperiales de estado en el contexto de la Sierra Norte. Investigaciones recientes en el sitio imperial tardío Inca-Caranqui, localizado en el límite más al norte del Tawantinsuyu, apuntan precisamente a elucidar la historia y el significado de esta región de frontera dentro de la agenda del Imperio Inca durante las etapas tardías de conquista y expansión (mapa 1).

Este artículo ubica al sitio Inca-Caranqui dentro de su contexto local e histórico y reporta los resultados preliminares de las investigaciones arqueológicas recientes realizadas en dicho sitio. Nuestros hallazgos a la vez corroboran y retan varios de los reportes etnohistóricos pertinentes a este sitio y aumentan nuestro entendimiento de las intenciones imperiales y las actividades que se realizaban en la frontera norte.

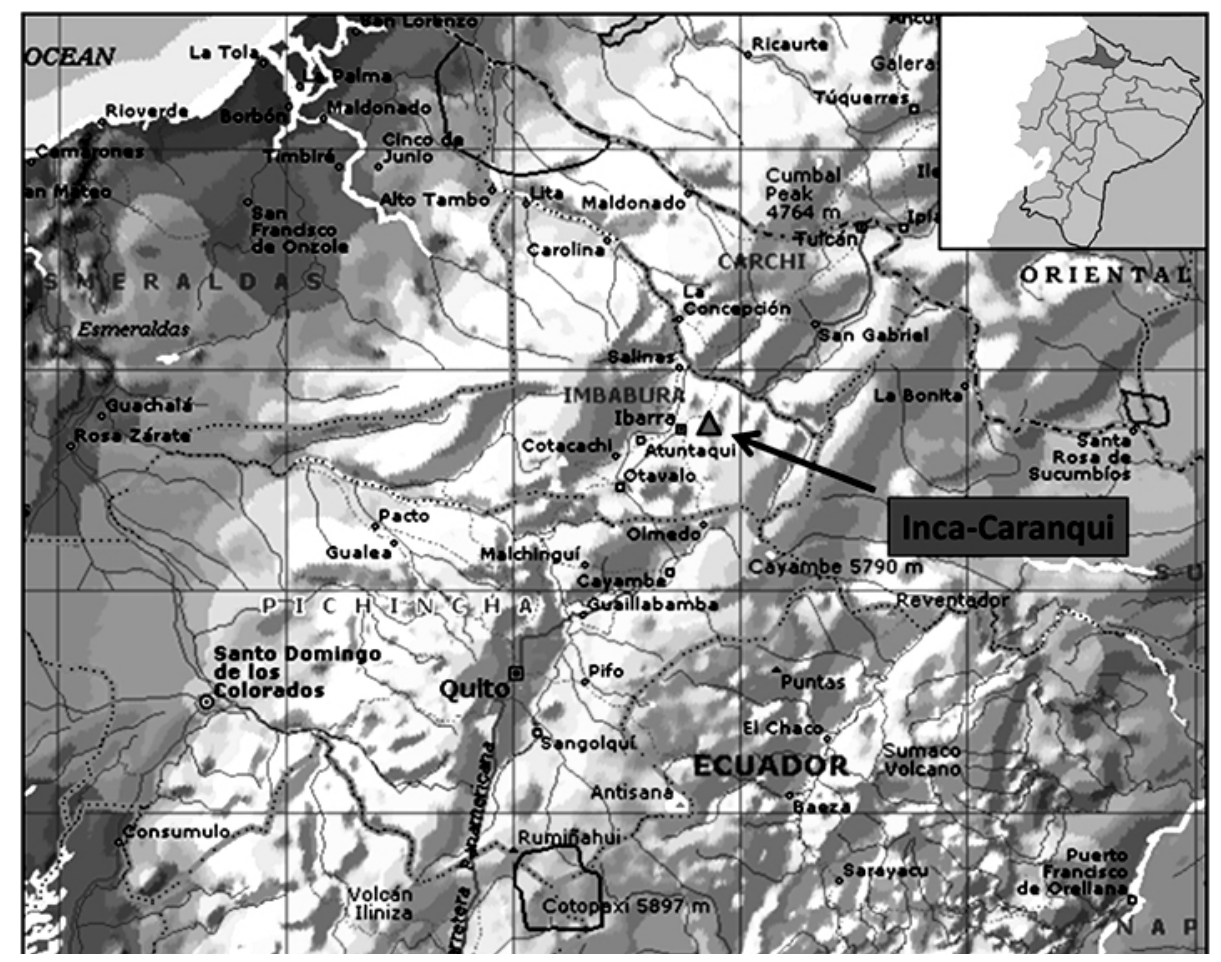

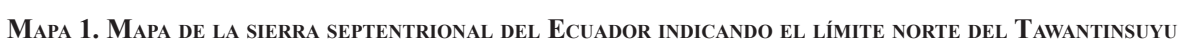
(línea de punteados) y la ubicación del sitio de Inca-Caranqui en la Provincia de Imbabura. 


\section{Antecedentes etnohistóricos}

Una de las autoridades tempranas acerca de la presencia Inca en la zona más al norte de los Andes, Miguel Cabello Balboa (1951 [1586]: 321), describe la exuberancia y fertilidad de la "renombrada" Provincia de Quito en términos entusiastas, pero denota también la fuerte resistencia encontrada por los Incas mientras se movilizaban para conquistarla. Aunque los recuentos de cómo y cuándo esta área fue incorporada al Tawantinsuyu varían, las fuentes más tempranas, así como las más conocedoras sobre la región, generalmente están de acuerdo en que fue Topa Inga Yupanqui quién condujo las primeras entradas a la zona y estableció los primeros puestos imperiales de avanzada en la región (Atienza, 1931 [1575?]: 21; Betanzos, 1996 [1551-57]: 143; Cabello Balboa, 1951 [1586]: 321-330; Cieza de León, 1995 [1553]: 133). Sin embargo, como reportan los cronistas de acuerdo al formato narrativo estándar para la historia dinástica Inca, la tarea de re-conquistar y reafirmar la autoridad imperial sobre las organizaciones políticas rebeldes de la sierra norte, subsecuentemente recae en el hijo y heredero del Sapa Inca, Huayna Capac.

Cabello Balboa (1951 [1586]) ofrece el recuento más detallado de las intervenciones militares de Huayna Capac en el avance final hacia el norte del extenso imperio. La base de operaciones de Huayna Capac para el asalto del norte fue el centro provincial de Tomebamba en la sierra sur del Ecuador. El hecho de que él no usara Quito para organizar sus tropas sugiere que este sitio no había sido, para este punto, totalmente asegurado (Salomon, 1986:142). Desde Tomebamba, el líder Inca lanzó una serie de campañas que pretendían re-consolidar la región alrededor de Quito propiamente y definitivamente conquistar los territorios aún no anexados al imperio y que comprendía la provincia de Caranqui-Cayambe. El número de avances y retiradas asociados a esta campaña sugieren que las Guerras Caranqui probablemente se dieron a lo largo de un periodo de por lo menos media década, si no más (Espinosa, 1983).

Fragmentos de información de varias fuentes indican que la subyugación al imperio del país Caranqui no sucedió en una manera directa o lineal de sur a norte, si no que fue más bien tácticamente organizada, creando un mosaico de gentes conquistadas y no conquistadas mientras el proceso se desenvolvía. La evidencia arqueológica indica que tanto el pucará Rumicucho y el sitio de El Quinche, los mismos que se ubican inmediatamente al oeste y sur del País Caranqui, respectivamente, fueron baluartes Inca desde épocas tempranas (Chacón y Mejia, 2006; Jijón y Caamaño, 1914; ver también Borchart de Moreno, 2007: 52-54; Salomon, 1986: 164-166). Evidencia lingüística sugiere que los distritos de Cahuasqui y Quilca en la esquina nor-oeste del País Caranqui fueron subyugados más tempranamente que otras áreas, en base a la prevalencia de kechwa-hablantes registrados en la zona luego de la conquista española (Aguilar 1965 [1582]: 245-247). Datos históricos provistos por Cabello Balboa (1951 [1586]: 380) sugieren que los Otavalos habían sido subordinados a los Incas por algún tiempo antes de que se diera la derrota final sobre la población general Caranqui-Cayambe, así como que Huayna Capac se había dispuesto a conquistar a los Pastos en el norte antes de cercar a los Caranqui (Ibíd.: 365) (mapa 2). El recuento de Cabello también nota que los Incas habían ubicado estratégicamente pucarás en Rumichaca, en la esquina nor-este del país Caranqui, y cerca de Pesillo en el lado centroeste del territorio, aunque ambos baluartes fueran derrotados en varias ocasiones por milicias locales durante el curso de la guerra (Ibíd.: 365-386). La suma de la evidencia sugiere que el control imperial sobre esta región era tenue e irregular hasta el fin, que la estrategia militar de los invasores fue aislar a la recalcitrante población Caranqui-Cayambe, y que esta estrategia resultó en la habilidad de los Incas para ejecutar un ataque final, en varios puntos geográficos estratégicos que les permitió salir finalmente victoriosos.

El sitio de Carangue (Caranqui) figura prominentemente en estos recuentos de la historia Inca tardía. Está cercanamente asociado con Yaguarcocha, o "Lago de Sangre" donde las fuerzas imperiales Incas finalmente dominaron a la desafiante población aborigen luego de varios largos años de guerra. En represalia a su comportamiento, Huayna Capac ordenó la masacre del 
total de la población masculina cerca de la orilla de la laguna donde los combatientes habían buscado refugio. Se dice que tantos combatientes fueron muertos que las aguas de dicho laguna se tiñó de sangre, dándole el nombre por el cual es conocido aún hoy, "Yahuarcocha". En base a varios pedazos de información, incluyendo lo que sabemos sobre la biografía de Huayna Capac (Betanzos, 1996; Cabello Balboa, 1951 [1586]; Rowe, 2008), la supuesta participación de Atahualpa en las campañas del norte y su edad al tiempo de su captura en Cajamarca (Betanzos, 1996:182; Cabello Balboa, 1951 [1586]:363; Rowe, 2008:161; Xerex, 1985:123), y la historia de los "guambracuna" que pelearon en la guerra imperial tardía de sucesión (Costales y Costales Peñaherrera 2002: 54), se conjetura que las Guerras Caranqui probablemente finalizaron entre 1518 y 1522.

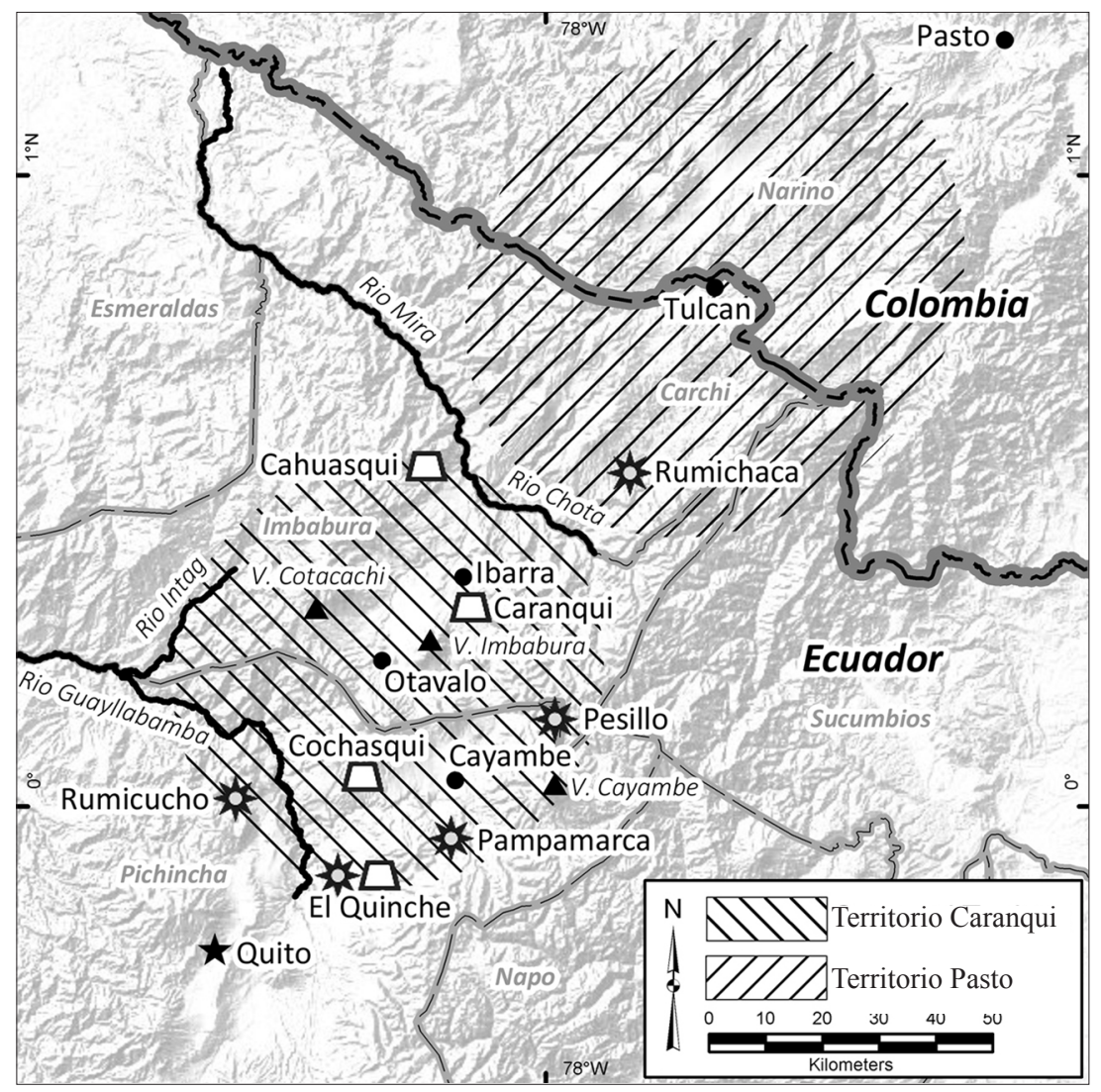

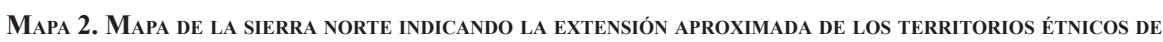
los Caranqui y los Pasto. Mapa elaborado por Boleslo E. Romero.

La conquista del país Caranqui fue la última gran campaña militar de Huayna Capac, y la batalla que se llevó a cabo en Yaguarcocha su última gran victoria. Montesinos (1957 [1644]:111) dice que, no mucho después de esta batalla, Huayna Capac ordenó la construcción en Carangue de un asentamiento "basado en el diseño del Cuzco" para su corte - sin duda para conmemorar su dura victoria sobre la región. Betanzos (1996 [1551-57]:202-204), sin embargo, da una versión

3 Nombre por el cual se conoce a los niños de la población Caranqui que fueron perdonados por Huayna Capac en Yaguarcocha. 
diferente de Carangue donde no se incluye mención alguna a Huayna Capac, aunque se anota que fue este gobernante quien venciera a los "hombres de Yaguarcocha" (Ibíd.: 183). En su lugar, Betanzos indica que fue Atahualpa quien ordenó la construcción de un palacio en Carangue que serviría como el sitio para su boda con Cuxirimay Ocllo (la esposa de Betanzos al momento en que se escribe su crónica) y de su investidura como el nuevo Sapa Inca (Ibíd.: 202-204). Habiendo dicho esto, también se vuelve claro en la narrativa de Betanzos que el asentamiento Inca de Carangue ya existía cuando Atahualpa da sus órdenes.

En cualquier caso, dada la localización de este sitio en el lejano borde norte del Tawantinsuyu, podemos asignar con confianza su construcción a las etapas tardías de la expansión imperial, con la fuerte posibilidad de que pueda representar el último edificio de esta escala llevado a cabo por el Inca previa a la invasión española. Los datos arqueológicos del sitio Inca-Caranqui ayudan a clarificar y corroborar la información etnohistórica incongruente, ofreciendo evidencia material que potencialmente soporta ambos recuentos históricos, aunque a la vez reta la cronología tradicional de la expansión Inca en esta región. Detalles respecto a la arqueología del sitio se presentan a continuación luego de una breve discusión sobre el entorno físico y la conformación étnica del país Caranqui.

\section{Eı Señorío precolombino tardío de Caranqui-Cayambe}

\section{Características Regionales}

El territorio que comprende la frontera norte del Tawantinsuyu coincide con la provincial más al norte del Ecuador moderno, incluyendo la región fronteriza con Colombia (ver maapa 1). Desde Quito al norte, esta zona se extiende a una distancia de aproximadamente $100 \mathrm{~km}$, desde el Ecuador hasta la latitud $0^{\circ} 50^{\circ} \mathrm{N}$. En términos políticos modernos, la región incluye las porciones de la sierra de las provincias de Carchi, Imbabura y el norte de Pichincha. Como es típico en los Andes ecuatorianos, esta zona está rodeada al este y oeste por cordilleras, ambas con picos significativos. El estratovolcán clásico, el cerro Imbabura (4.621 m.s.n.m.), se asienta entre las dos cordilleras, dominando el centro de la cuenca interandina que lleva su nombre. El territorio también contiene un número notable de lagunas, incluyendo el de Imbacucha, Chicapán o San Pablo, asociado al Imbabura, Cuicocha, situada en el cráter del volcán Cotacachi, y Yahuarcocha, localizada al lado de la ciudad de Ibarra.

El terreno general de esta región puede ser caracterizado como áspero y complejo, consistiendo de una mezcla de colinas, laderas escarpadas, valles profundamente incisos y barrancos erosionados. El clima es templado, con variaciones dependientes de la altitud; la lluvia es estacional pero generalmente abundante. Los suelos con ceniza volcánica de la región son naturalmente fértiles y han sostenido altos niveles de productividad agrícola por milenios. El principal desfogue dentro de la región es el rio Chota-Mira, el mismo que forma la línea divisoria entre las provincias de Carchi e Imbabura, y también entre las unidades étnicas Pasto y CaranquiCayambe (ver figura 2). El Chota-Mira es uno de los pocos ríos del Ecuador que cruza la cordillera occidental para desembocar en el océano Pacífico. Variando entre 1600 y 1700 m.s.n.m. en el lado este, el clima cálido y seco del valle del Chota-Mira lo ha convertido en una zona de recursos de especial importancia por lo menos un milenio, habiendo permitido previamente la producción de cultivos sub-tropicales valiosos tales como la hoja de coca, algodón, índigo y ají (Capsicum) (Bray, 2005; Coronel, 1991; Echeverría et al., 1995; Landázuri, 1990).

El territorio asociado con la población Caranqui-Cayambe, definido en base a evidencia arqueológica (Athens, 1980; Gondard y López, 1983) y toponímica (Caillavet, 1983; Salomon y Grosboll, 1986), comprende la región entre el río Chota-Mira hacia el norte y el río Guayllabamba en el sur-oeste. Los límites laterales son menos definidos, aunque el perímetro oriental probablemente corresponde con la división continental y el borde oeste con la cercanía al río Intag. La extensión de la región es de aproximadamente 3.600 kilómetros cuadrados. 


\section{Organización Política}

Durante el período pre-Colombino tardío, y posiblemente más atrás en el tiempo, los residentes indígenas de esta región parecen haber hablado una lengua común, compartido similares tradiciones artísticas, practicado tecnologías de subsistencia similares, y seguido estrategias de asentamiento comparables (Athens, 1980, 1992; Borja, 1965 [1591]: 249; Bray, 1991; Caillavet, 1983). Esto puede verse en la toponimia regional; el uso de materias primas similares; los tipos y estilos de cerámica producidos; la tecnología lítica y metalúrgica; patrones espaciales tanto a nivel doméstico como comunitario; y las prácticas funerarias. Tomados en conjunto, la suma de la evidencia material y lingüística sugiere una identidad étnica compartida.

No obstante, fuentes documentales tempranas indican que la población regional estaba organizada en un número de unidades políticas semi-autónomas del orden de señoríos de pequeña escala (Salomon, 1986). Entre los más importantes de estos estaban los Caranqui, Cayambe, Otavalo y Cochasquí. En los últimos 30 años, ha existido un considerable debate sobre cual, si alguno, de estas unidades políticas fue la más poderosa durante el periodo pre-Colombino tardío (Caillavet, 1981, 1985; Espinosa, 1983; Larrain, 1981; Moreno, 1988). Lo que sugieren las variadas opiniones y pedazos de datos etnohistóricos es que el poder era probablemente ejercido a lo largo de diferentes dimensiones - probablemente relacionadas a la guerra, la diplomacia, el conocimiento ritual y la riqueza - en esta región. Como se ha discutido en otros artículos, las áreas de autoridad y control sobrepuestas que se han notado aquí, probablemente reflejan la naturaleza jerárquica de la organización política pre-Colombina tardía del País Caranqui (Bray, 2008).

\section{Tolas}

Uno de los rasgos más prominentes del paisaje cultural de esta región son los grandes montículos de tierra conocidos localmente como tolas (Figura 3). La distribución de estos rasgos es esencialmente correspondiente con la extensión del territorio e influencia Caranqui en la sierra norte. Cerca de cien sitios Tolas se identificaron en Imbabura y el norte de Pichincha en base a interpretación de fotografías aéreas (Gondard y López, 1983), aunque solo alrededor de 70 de estos se verificaron en el suelo (Athens, 1980, 1992, 2003; Bray, 1991; Osborn y Athens, 1974), y muchos han sido destruidos en los años siguientes. La mayoría de los sitios de montículos se encuentran dentro de un radio de 20 kilómetros del cerro Imbabura entre las ciudades modernas de Ibarra y Otavalo a elevaciones entre 2200 y 3000 metros sobre el nivel del mar- la zona óptima para el cultivo de maíz (Gondard y López, 1983:103). Mientras el número de movimientos de tierra por sitio varía bastante, desde uno o dos montículos hasta casi 150 en el sitio más grande en Zuleta, la mayoría de sitios tenía entre 5 y 20 de dichos rasgos.

Los montículos cuadrados, los más grandes, entre los cuales hay de hasta 90 metros de lado a lado y diez o más metros de altura, servían como plataformas para grandes estructuras circulares con techo y pisos de arcilla cocida y áreas interiores para cocinar; ocasionalmente también se han encontrado entierros en asociación con estos montículos (Athens, 1980: 147-165, 2003; Jijón y Caamaño, 1914: 297, 1920: 48-57; Kunter, 1981: 179-180; Oberem, 1969: 322, 1981:6168; Pazmiño, 2009). Las limitadas excavaciones conducidas en estos sitios han producido gran cantidad de recipientes de gran tamaño y número, para cocinar y grandes ánforas para servir y guardar la chicha (Athens 2003, 2012; Meyers 1981). La evidencia sugiere que los sitios de montículos en esta región estaban asociados con áreas ancestrales de enterramientos, residencias de elite, así como actividades sociales y ceremoniales intermitentes que involucran festines. Otros datos de prospecciones regionales e información etnohistórica indican un patrón de asentamiento generalmente dispersa en base a aldeas pequeñas y caseríos (Bray, 1991; Caillavet, 2000 [1988]; Gondard y López, 1983; Larraín 1980: 206; Yanchar, 2013). En general, parece ser que los sitios grandes de montículos en el país Caranqui probablemente servían como centros regionales y puntos focales rituales para las reuniones periódicas de las poblaciones altamente dispersas. 


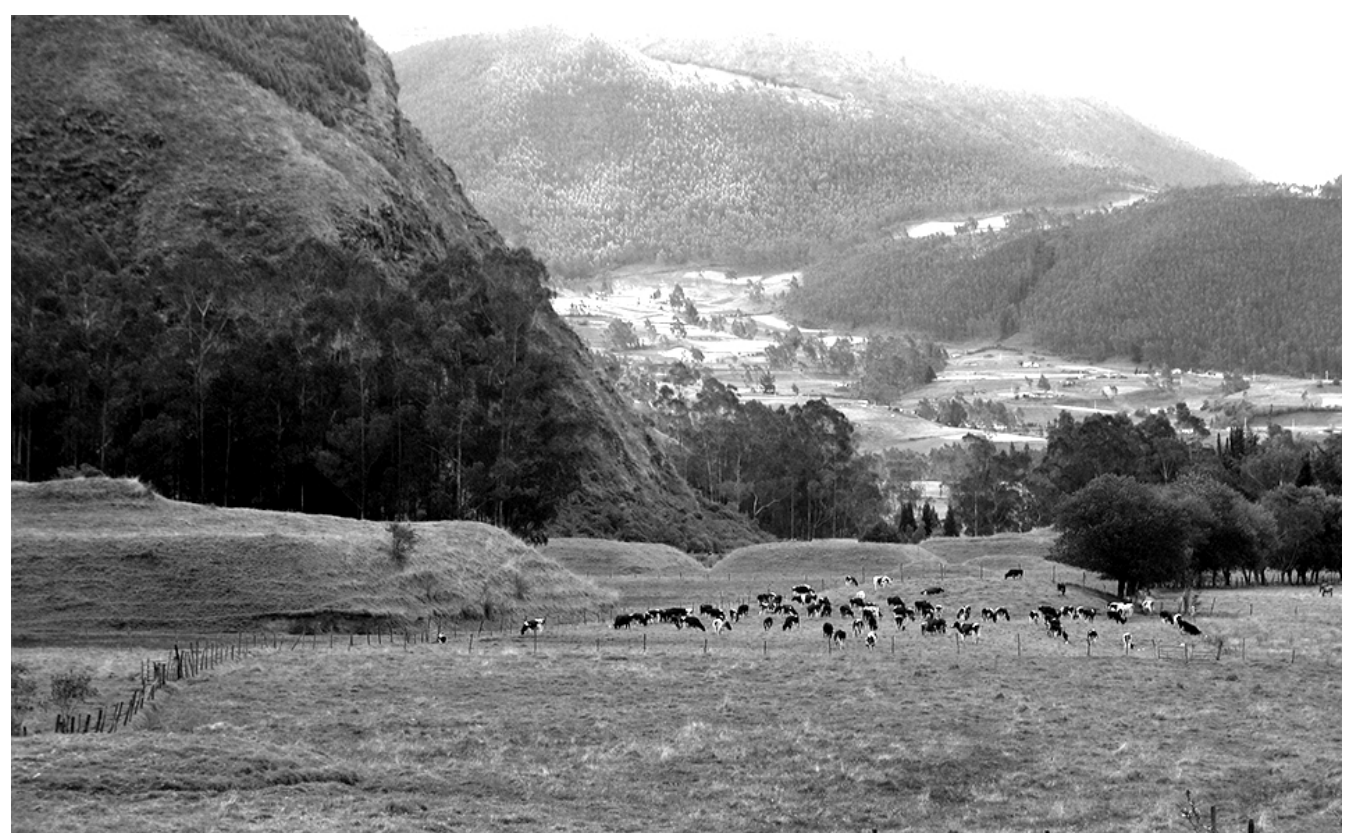

Foto 1. Un grupo de tolas Cuadrilaterales y hemisféricas en El Sitio de Zuleta, ubicado aproximadamente 15 KM al SSE de Caranqui. Foto por Tamara Bray.

\section{El sitio Inca-Caranqui}

El sitio Inca-Caranqui se sitúa entre lo que fuera uno de los centros principales de la población Caranqui proto-histórica. Este asentamiento estuvo localizado en las estribaciones al norte del cerro Imbabura a una elevación de aproximadamente 2300 metros sobre el nivel del mar. El actual pueblo de Caranqui es una parroquia de la ciudad de Ibarra, que se ubica a tres kilómetros en el valle inferior. Cuatro kilómetros al nor-este de Caranqui se encuentra el históricamente relevante cuerpo de agua conocido como Yaguarcocha. Caranqui ha sido desde hace algún tiempo reconocido como el "distrito antiguo" de Ibarra. De especial atención es el hecho de que Ibarra fue fundada en 1606 con tierras expropiadas de "los indios de Caranqui," entre los cuales explícitamente se nombre a Doña Joana Atabalipa (Tobar, 1985 [1929]:29)—su apellido probablemente hace referencia a su linaje real y su presencia en Caranqui en este tiempo es importante para nuestra interpretación respecto al sitio Inca-Caranqui. ${ }^{4}$

El asentamiento aborigen de Caranqui claramente representa una de las principales llactas de la población local pre-incaica. Esto en base a que hasta 1970, el pueblo incluía una significante cantidad de enormes tolas (Athens, 1978: 272). Desafortunadamente, solo unos pocos remanentes de estos trabajos en tierra monumentales sobreviven hoy en día gracias a la rapaz y no controlada industria ladrillera, que se desarrolla específicamente para explotar estos rasgos (Echeverría y Bray, n.d.). La tola más grande que permanece en Caranqui, que se localiza a dos cuadras del centro del pueblo, es un montículo cuadrado que posiblemente tuvo una rampa larga en el lado norte. Aunque parcialmente destruido en los cuatro lados, los restos de esta tola (conocida como "Tola EMAPA") son aun impresionantes, midiendo $46 \mathrm{~m}$. (N/S) por $46 \mathrm{~m}$. (E/O) en el tope, y

4 El apellido "Atabalipa" es una variante de escritura de "Atahualpa" y es tomado como indicativo de descendencia de este soberano Inca. 
8 metros de altura. Como sugiere evidencia reciente, estas edificaciones probablemente servían como montículos plataforma para residencias cacicales, posiblemente también como sepulcros para la élite local (Athens, 2012; Oberem, 1981; Pazmiño, 2009). El sitio imperial Inca-Caranqui fue así construido directamente en proximidad a las tolas monumentales de este importante centro Caranqui - probablemente como una declaración material de poder. Otras razonas para la elección de Caranqui como centro imperial Inca tienen que ver con su localización geográfica, vis-á-vis zonas de recursos especiales, sistemas de intercambio entre este y oeste, y rutas de tránsito norte-sur, siguiendo lógicas paralelas a las del establecimiento del Quito incaico (Salomon, 1986: 146-147).

\section{Arquitectura inca en Caranqui}

La presencia Inca en Caranqui ha sido conocida en parte gracias a la preservación de dos muros con nichos de construcción pirca localizados en una propiedad privada cerca del centro del pueblo (Athens, 1978: 276; Bedoya, 1979) (foto 2). Estas dos paredes alguna vez fueron parte de la esquina noreste de un gran edificio Inca, al que se ha referido como el "palacio de Atahualpa". La estructura está localizada inmediatamente al este de la moderna iglesia Católica y al suroeste del recientemente descubierto edificios y rasgos imperiales donde nuestras excavaciones se centran (figura 1). Mientras el tamaño del gran edificio es indeterminado debido al daño que ha sufrido, fue posible determinar que la pared este, que todavía retiene evidencia de tres puertas trapezoidales, fue de por lo menos 40 metros de largo, mientras que la pared norte tuvo por lo menos 50 metros de largo, y en unas partes mantiene una altura de $3 \mathrm{~m}$.

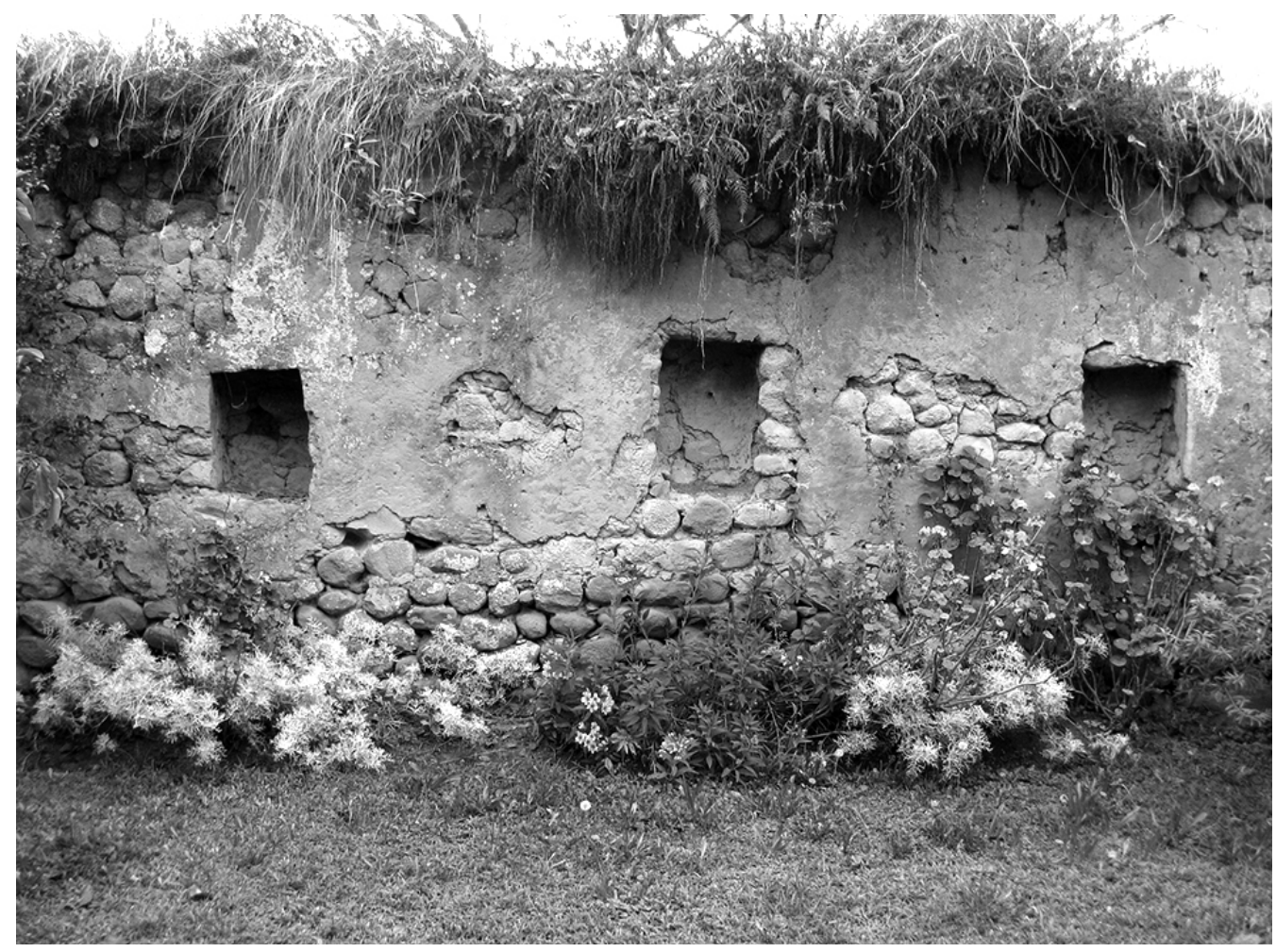

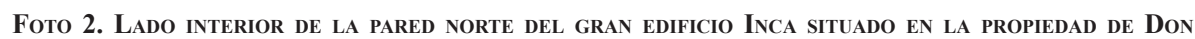
Tobias Flores en Caranqui. Foto por Tamara Bray. 


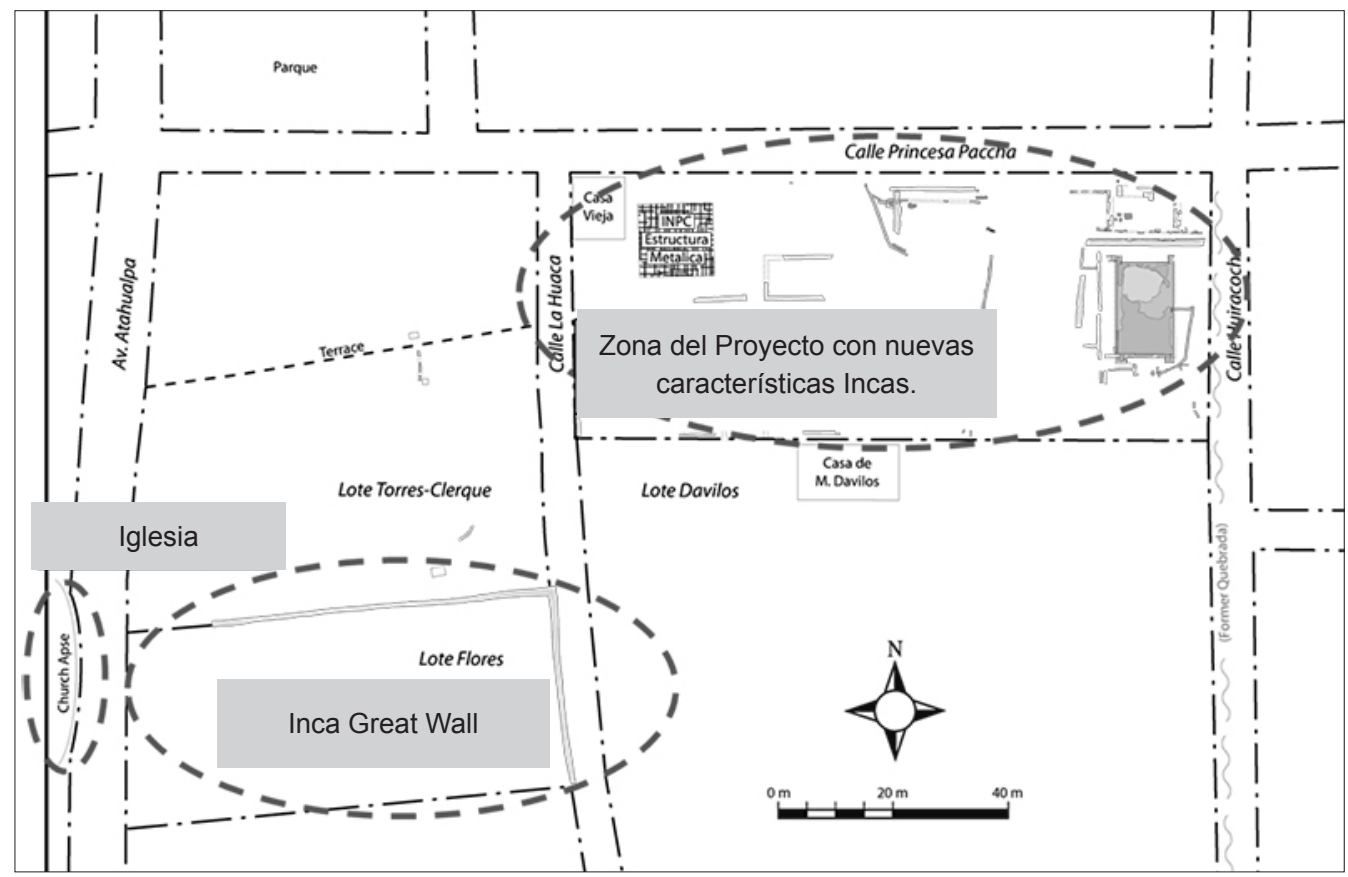

Figura 1. Elementos ARQuitectónicos asociados CON EL SITIO INCA-CARANQUi. Los MURos INCAS ESTÁN INDICADOS EN EL COLOR GRIS CLARO, LOS CANALES EN AZUL, Y EL TEMPLO SEMI-SUBTERRÁNEO EN MORADO. LAS INVESTIGACIONES CONDUCIDAS ENTRE 2008 Y 2011 FUERON ENFOCADAS PRINCIPALMENTE EN EL SOLAR COMPRADO POR EL MUNICIPIO EN

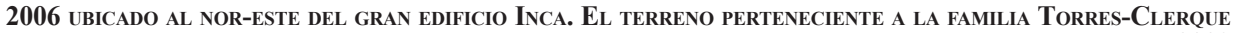
INMEDIATAMENTE AL NORTE DEL EDIFICIO GRANDE FUE INVESTIGADO MEDIANTE PRUEBAS DE PALA SISTEMÁTICAS EN 2009 Y EN 2010, CON SIETE UNIDAdes de EXCAVACIÓn de 1 POR 1 Metro. MAPa Elaborado por Boleslo E. Romero.

Como se puede ver en la figura 4, remanentes de enlucido y pigmentos existen aún en porciones del interior de las paredes y nichos, así como varios dinteles en deterioro asociados con las puertas que han sido emparedadas. A simple vista, el empañetado ha sido realizado con barro mezclado con paja de los terrenos aledaños, llamada localmente "hierba de perro"; la masa de barro aplicada al muro de piedra es una capa gruesa entre 2 y $4 \mathrm{~cm}$. En la base del muro se observan piedras naturales grandes con la cara plana natural o trabajada hacia la parte exterior. En relación a la técnica de construcción: se empleó una doble hilera de piedras, a cada lado del muro se presenta la cara plana o tallada de la piedra, que va desde el centro del muro hacia el exterior de cada lado. Dimensión de las piedras, promedio: $35 \mathrm{~cm}$ de largo, y grosor $15 \times 20 \mathrm{~cm}$; pegadas con barro (Echeverría, 2009).

La pared este de la estructura bordea un pequeño callejón, presumiblemente antiguo, denominado La Huaca, el mismo que se orienta a 7 grados de oeste a norte. Menos de 50 metros al oeste de esta pared se encuentra el ábside de la iglesia, el mismo que se dice fue construido sobre cimientos de una estructura incaica alrededor de AD 1570 (Bedoya, 1979:152). Personas mayores de la comunidad se solían referir al espacio ocupado por la iglesia como el "Templo del Sol" (Ibid.). Una inspección visual de la iglesia y del patio interno, junto con limitadas excavaciones en el lado norte del ábside, no revelaron evidencia de restos arquitectónicos Inca o artefactos, aunque varias piedras cortadas de manera rectangular fueron notadas en la parte superior de la pared exterior del anexo norte de la iglesia, las mismas que podrían ser bloques Inca re-utilizados. Como se puede ver por la imagen del satélite del centro del pueblo de Caranqui (figura 2), el axis largo de la iglesia se alinea precisamente con la orientación de la pared norte del gran salón Inca (255 grados). 


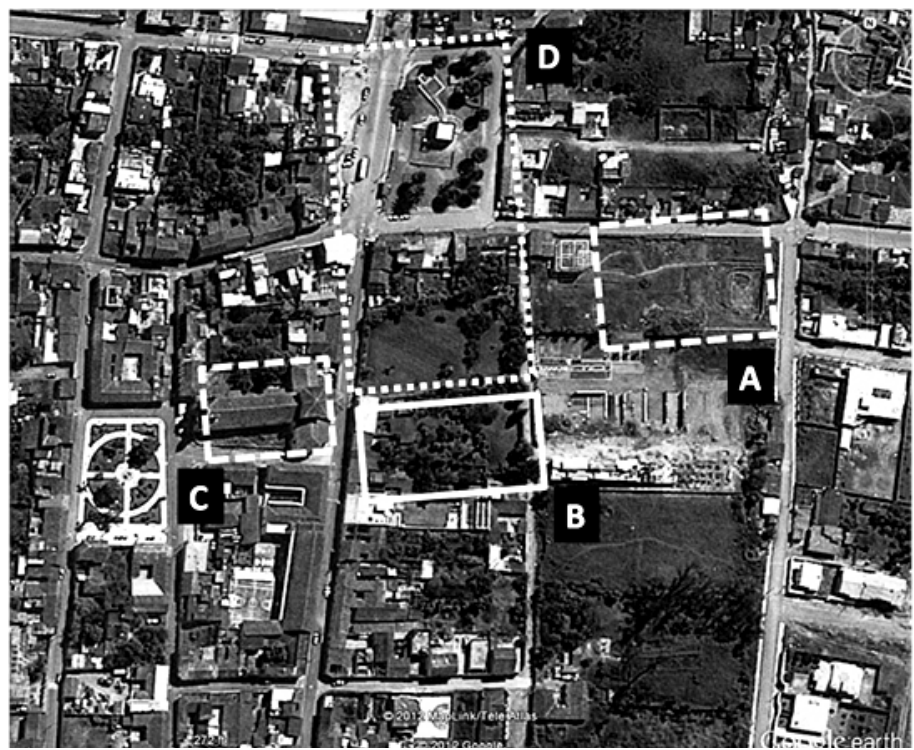

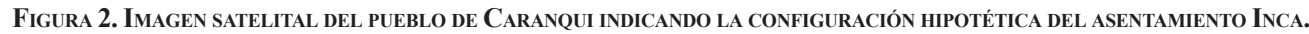

(A) LOTE MUNICIPAL QUE CONTIENE EL TEMPLO SEMISUBTERRÁNEO, LOS CANALES Y LOS EDIFICIOS RECTANGULARES;

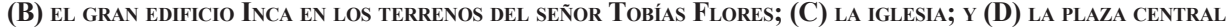
hipotética del sitio Inca-Carangui con el Parque de Atahualpa situado en la mitad norte y el solar de la familia Torres-Clerque en la mitad sur (Mapa de Google Earth). Nótese la Alineación este-oeste de la MID-LINE DEL TECHO DE LA IGLESIA (C) CON EL MURO NORTE DEL GRAN EDIFICIO INCA (B).

En el 2008, se condujo una prospección con GPR en lo que debió haber sido el interior del gran edificio Inca. Los resultados indican la presencia de varios pequeños cuartos o paredes de construcción efímera al interior (Conyers, n.d.). Adicionalmente, una pared de piedra alineada perpendicularmente a la pared este del edificio fue detectada por el radar a 35 y $70 \mathrm{~cm}$. Dado que el interior del edificio Inca comprende el patio posterior de una residencia privada, no hemos podido aún confirmar los hallazgos del GPR. Pruebas de pala y excavaciones limitadas (siete unidades de 1x1 metro) fueron, sin embargo, conducidas en el lado norte del gran edificio Inca, en un lote vacío ( 73 x 45 metros en tamaño) localizado inmediatamente adyacente. Solo tres fragmentos Inca fueron recuperados de la muestra sub-superficie (un asa zoomorfa y un fragmento de cuello con decoración en forma de diamantes negros sólidos-ambos asociados a la forma aríbalo, y un fragmento polícromo), constituyendo menos del 0.4 por ciento del total de cerámica recuperada en esta área- (en contraste, la cerámica del período Colonial comprendió el 30 por ciento del total). La general ausencia de material Inca en este sector ofrece soporte a la idea de que pudo haber constituido una parte de la plaza central del asentamiento Inca, así como el hecho de que el gran edificio Inca lo rodea en el lado sur (dichos edificios a menudo ayudando a definir los espacios de la plaza en sitios imperiales), junto con las secciones más antiguas (el lado este) de la iglesia Católica. ${ }^{5}$

En este lote en particular ("Lote Torres-Clerque"), también se registra la presencia de un alto muro de contención de una terraza hecho de guijarros (aproximadamente 2 metros de altura) que define el lado norte (ver figura 1). El muro de contención está ubicada a 45 metros al norte del gran edificio Inca, y corre de manera paralela a la pared norte de esta estructura, entre el callejón La Huaca y la avenida Atahualpa en el lado oeste. Sospechamos que este muro también pudo haber sido un rasgo arquitectónico Inca.

5 Ver Wernke (2007) para una discusión respecto a la asociación de iglesias coloniales tempranas con los espacios de plaza Inca en sitios imperiales apropiados. 
En la segunda mitad de 1990, investigaciones conducidas por el Instituto Nacional de Patrimonio Cultural (INPC) revelaron los cimientos de tres estructuras Inca rectangulares adicionales, así como de una serie de impresionantes canales cubiertos de piedra en un lote al este del callejón La Huaca y al nor-este del gran edificio Inca (Tobar, 1998). Como consecuencia de estos hallazgos, este sector de Caranqui fue declarado "zona arqueológica protegida" por el INPC en 1998. Aún así, la parcela de tierra que contenía las estructuras Inca recientemente descubiertas continuó siendo utilizada para la manufactura de ladrillos - la misma que involucró la remoción de la capa inicial de suelo en la mitad oeste del lote a una profundidad de más de un metro- hasta que finalmente fue comprado por la Municipalidad de Ibarra en el año 2006.

Durante las operaciones de limpieza que siguieron (Echeverría, 2006-2007), una notable estructura semi-subterránea de piedra finamente cortada fue descubierta en el lado este de esta propiedad (foto 3). Este rasgo, que parece ser único en el contexto del Imperio Inca (Bray, 2013), claramente comprende un elemento ceremonial significativo en el centro Inca-Caranqui. Esta propiedad municipal ha sido el foco de investigaciones colaborativas, internacionales y multidisciplinarias desde el año 2008. Durante el curso de nuestra investigación en este sector, hemos utilizado una variedad de técnicas arqueológicas en combinación con investigación etnohistórica y esfuerzos de conservación para reconstruir la historia y la significancia del sitio imperial Inca-Caranqui. Nuestro programa de investigación en campo ha involucrado el uso de sensores remotos, incluyendo radar de penetración de suelo y análisis geo-químicos de suelos; estudios geomorfológicos; prospecciones regionales de arcillas y petrografía; excavaciones estratigráficas; mapeo topográfico y tridimensional; estudios paleobotánicos y de arqueo fauna; y estudios líticos. Muchos de los análisis de materiales están aún en curso. Este artículo, por lo tanto, constituye un reporte preliminar sobre algunos de los hallazgos clave hasta la fecha en relación a la configuración, arquitectura, y cronología del sitio Inca-Caranqui (ver también Bray y Echeverría, 2009, 2010, 2011; Conyers, n.d.; Krull, 2014; Minc et al., 2014; Romero y Bray, 2014).

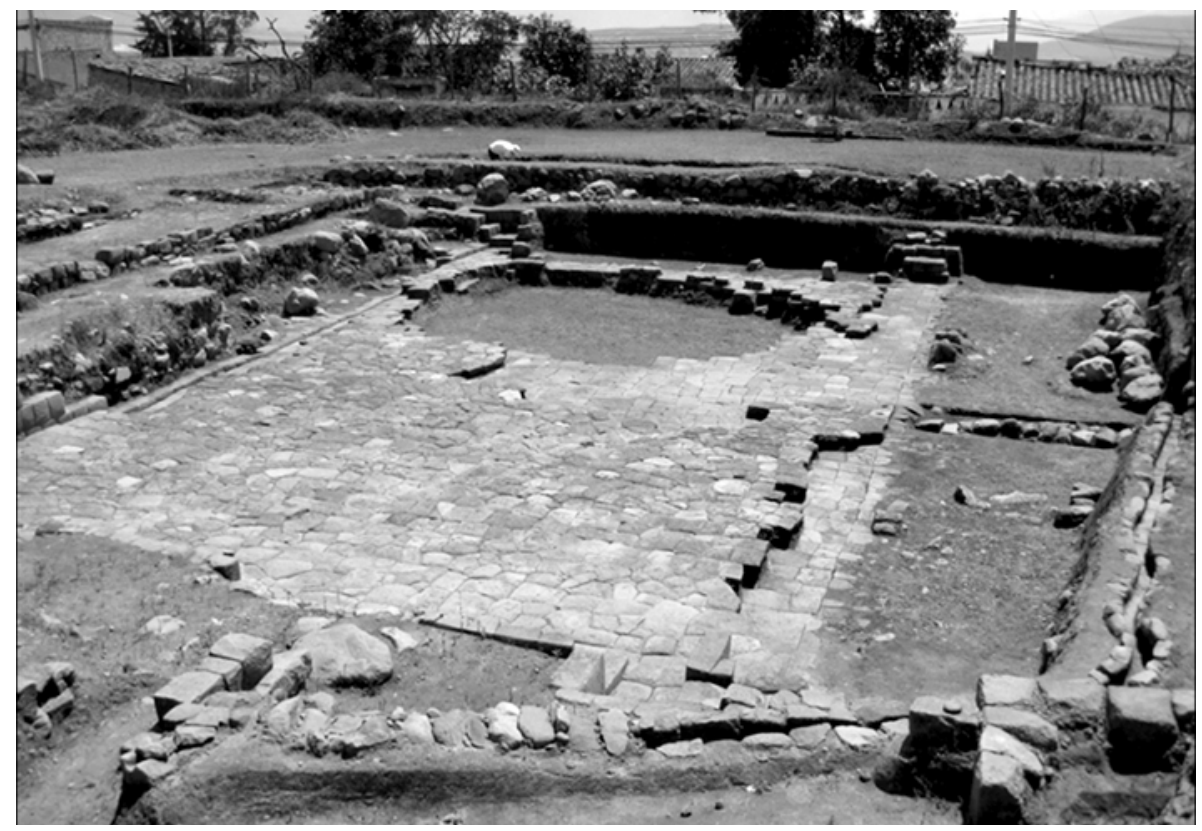

Foto 3. LA ESTRUCTURA SEMISUbTERRÁNEA EXPUESTA POR PRIMERA VEZ EN LA MITAD ESTE DEL LOTE MUNICIPAL EN 2006, MIRANDO HACIA EL NORTE. NóTESE El CANAL PARCIALMENTE CUBIERTO QUE CORRE A LADO DE LA SECCIÓN SURESTE DE LA ESTRUCTURA, LAS ETAPAS EN LAS ESQUINAS NORESTE Y NOROESTE DE LA PLAZA SEMI-HUNDIDA, Y LOS DOS EPISODIOS DE CONSTRUCCIÓN DE PISOS VISIBLES. El HUECO GRANDE EN LA PARTE NORTE DEL TEMPLO ES DEBIDO A ACTIVIDADES DE HUAQUERISMO QUE PROBABLEMENTE OCURRIÓ DURANTE EL PERÍODO TEMPRANO COLONIAL. Foto POR TAMARA BRAY. 


\section{Tamaño y Disposición del Sitio}

En base a nuestro programa de mapeo y excavación, proponemos que Inca-Caranqui comprendió aproximadamente 10 hectáreas. Nuestra investigación sugiere que el contorno del asentamiento Inca es cercano al pueblo moderno de Caranqui, centrándose en el pequeño parque donde el monumento a Atahualpa está localizado actualmente (ver figura 2). Este parque, que creemos debió comprender una porción de la plaza del asentamiento Inca, está situado alrededor de 100 metros al nor-oeste del templo semi-subterráneo, 80 metros al norte del gran edificio Inca y el ábside de la iglesia, y alrededor de 150 metros al sud-este de la tola más grande restante en la zona (Tola EMAPA) en Caranqui. Sugerimos que los límites laterales del asentamiento Inca coinciden con la ahora rellena quebrada Negrete al este, la misma que previamente seguía el curso que hoy tiene la calle Huiracocha - la calle adyacente al lado este del lote municipal y la quebrada Cuzca al oeste, que está localizada a 80 metros al oeste de la tola EMAPA. Los límites para el sitio propuestos están basados en inspecciones de la superficie limitadas, pruebas y monitoreo asociados a proyectos de construcción locales; información sobre hallazgos (o falta de ellos) de parte de los residentes locales; y la toponimia local.

Respecto a los tipos y funciones de las estructuras imperiales encontrados en el sitio, tenemos dos recuentos históricos además de la información arqueológica en cuales basarnos. De acuerdo a Oviedo y Valdez (1851-55, Vol. 4: 239), la primera horda de españoles ávidos de tesoros, guiada por Sebastián de Benalcázar, llegó a Caranqui en Julio o Agosto de 1534, un año después de la ejecución de Atahualpa. Aquí supuestamente hallaron una pequeña "casa del sol" cubierta por dentro y por fuera con oro y plata (Íbid.). A Cieza de León, quien pasó por Caranqui una década después, se le dijo que aquí había un templo del Sol, al que 200 aqcllakuna eran dedicadas (Cieza de León, 1995 [1553]: 122). Dado el patrón de dominación Colonial temprana, pistas históricas y su localización y orientación básicas, tenemos pocas dudas que la iglesia moderna ocupa el sitio original del templo Inca, quienes a su vez pudieron haberse apropiado de un sitio sagrado para la población Caranqui indígena.

Cieza reportó que los aposentos reales del Inca en Caranqui consistían de palacios y habitaciones con fino trabajo en piedra y que estaban situados en una pequeña plaza (Ibid.). También anota que, entre estos aposentos se encontraba un "estanque" hecho de muy fina piedra. Este último rasgo es casi ciertamente el templo semi-subterráneo localizado en la parte este del lote municipal. Este hallazgo arqueológico en particular sirve para resaltar la precisión histórica de los recuentos descriptivos de Cieza. Alrededor de este importante rasgo, hemos documentado a través de excavaciones, un número adicional de paredes de piedra que representan tanto bases de edificaciones Inca como muros de cerramiento. Dos edificaciones relativamente pequeñas rectangulares (8.5 x 13 metros) descubiertos por Tobar (1998: 14) se encuentran en proximidad el uno del otro en la porción oeste del lote municipal (figura 3, estructuras 1 y 2). Otra estructura, también de ocho metros de ancho (observada solo en perfil en 1998), yace alrededor de 25 metros al sur de estas (Tobar, 1998: 15; figura 3, estructura 3).

Aunque mínimo, estos datos sugieren que el área del sector oeste del lote municipal pudo integrar una porción de la zona residencial para la elite Inca y los funcionarios imperiales de alto rango. Estos edificios parecen estar segregados espacialmente del templo semi-subterráneo al este por un canal con dirección norte-sur que posiblemente dividía estas zonas - si se tratara de hecho de una estructura sobre la superficie, una suposición de la que no estamos seguros. Debido a la remoción previa de más de un metro de suelo para la manufactura de ladrillos, la mitad oeste del lote Municipal donde estas bases de edificaciones están localizadas, ha sido esencialmente desprovista de material cultural. En el sector nor-este de este lote, dos masivas bases de paredes de piedra (120 cm. de ancho) con orientaciones este-oeste fueron excavadas en el 2008 y 2009 (ver figura 3). Una se encuentra inmediatamente al norte de la estructura semi-subterránea. Pudo haber servido como base de una pared de cerramiento designada para contener y/o ocultar de la vista las actividades que ocurrían en el área de la "piscina," la misma que inferimos era una zona 
de actividad ritual. La otra base de pared bordea el filo norte del lote y debe haber tenido más de 50 metros de largo. El extremo oeste de esta pared termina cerca de la juntura de dos de los canales mejor preservados del sitio. El extremo este parece encajar con uno de las dos paredes con orientación norte-sur descubiertas al norte de la plaza semi-hundida.

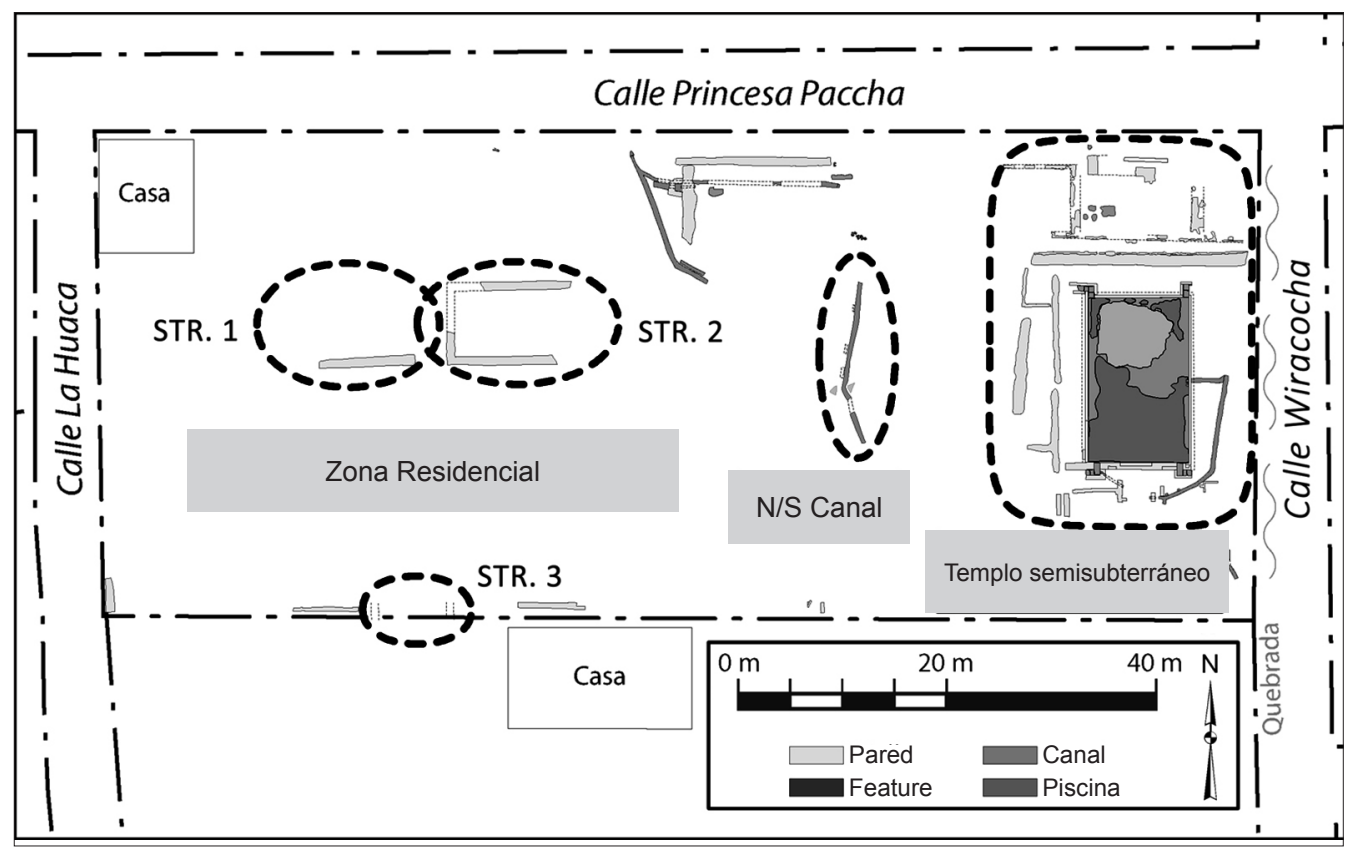

Figura 3. El lote municipal (110 x 45 metros) delimitado en el norte por la Calle Princesa Paccha y en los lados este y oeste por las Calles Wiracocha y La Huaca, Respectivamente, que ha sido el enfoque de NUESTRAS EXCAVACIONES RECIENTES. LOS CÍRCULOS CON LÍNEAS INTERMITENTES INDICAN LOS ELEMENTOS INCAS PRINCIPALES IDENTIFICADOS HASTA AHORA EN EL NUCLEÓ CEREMONIAL DEL SITIO INCA-CARANQUI DISCUTIDO EN EL texto. Mapa elaborado por Boleslo E. Romero.

Estas dos últimas paredes norte-sur están construidas con albañilería Inca expedita, en referencia, Niles (1987: 278) señala como "intermediado", que involucra el uso de piedras mínimamente trabajadas en la cara exterior y un núcleo interior que consiste en piedra suelta y relleno de escombros (foto 4). Estas paredes tienen un ancho de 90-100 cm, dos hiladas y corren de manera paralela la una de la otra con 11 metros de separación. Pueden formar parte de las paredes este y oeste de otro edificio, con medidas de 11 × 6 metros, pero esto no ha podido ser confirmado.

Un par de observaciones interesantes se pueden hacer respecto a las paredes y al área norte del templo semi-subterráneo. En primera instancia, hemos encontrado una alta densidad de trozos de arcilla cocida o bahareque, exclusivamente en asociación con las paredes Inca en los niveles superiores, entre $25-35 \mathrm{~cm}$., de las unidades de excavación. Este material puede representar pedazos de piso y/o enlucido de paredes similares al que se ve aún in situ en el interior de las paredes del gran edificio Inca en la propiedad de la familia Flores (ver foto 2). Curiosamente, Tobar (1998: 14) notó la presencia de restos de este recubrimiento en el interior de las paredes de un posible tanque de sedimentación (del que discutiremos más abajo) que descubrió en 1998. En segundo lugar, la pared oeste descubierta en el área al norte de los bordes de la piscina y potencialmente "contuvo" varios entierros previamente no disturbados. Aunque inicialmente asumimos que estos pertenecían al período Inca, los análisis de AMS y el ajuar funerario asociado indican claramente que estos datan de 1500 años antes de la ocupación Inca (ver tabla 1). 


\begin{tabular}{|c|c|c|c|c|c|c|}
\hline & 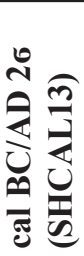 & 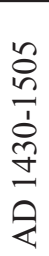 & 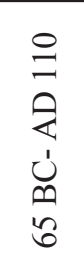 & 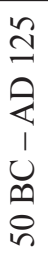 & 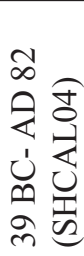 & \\
\hline & 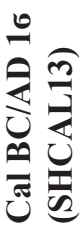 & 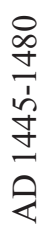 & $\begin{array}{l}n \\
n \\
e \\
i \\
1 \\
0 \\
0 \\
i \\
i n\end{array}$ & 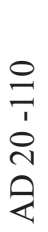 & 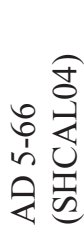 & \\
\hline & 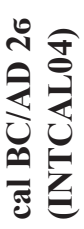 & 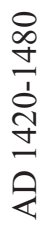 & $\begin{array}{l}0 \\
8 \\
1 \\
ن \\
0 \\
8 \\
0\end{array}$ & $\begin{array}{l}8 \\
\infty \\
\ell \\
1 \\
1 \\
0 \\
0 \\
8\end{array}$ & & $\begin{array}{l}\text { U } \\
\text { D } \\
\text { o } \\
1 \\
1 \\
\text { ¿ }\end{array}$ \\
\hline & 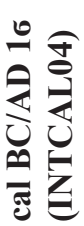 & 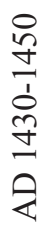 & $\begin{array}{l}0 \\
0 \\
\theta \\
1 \\
ن \\
0 \\
8 \\
8\end{array}$ & 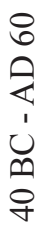 & $i$ & $\begin{array}{l}\text { n } \\
i \\
i n \\
\stackrel{1}{N}\end{array}$ \\
\hline & 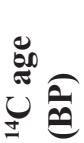 & 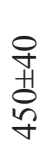 & 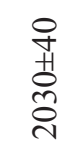 & 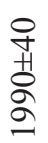 & $\begin{array}{l}\text { ㅍ } \\
\text { तิ } \\
\text { તิ }\end{array}$ & $\begin{array}{l}n \\
\stackrel{n}{H} \\
0 \\
\vec{n}\end{array}$ \\
\hline & $\bigcup_{0} \stackrel{\hat{\theta}}{g}$ & $\begin{array}{l}\infty \\
\stackrel{\gamma}{\gamma}\end{array}$ & $\stackrel{\vartheta}{\hat{\imath}}$ & $\stackrel{\sim}{\stackrel{\sim}{\sim}}$ & $\underset{\sim}{\stackrel{\sim}{*}}$ & $\vec{\sim}$ \\
\hline 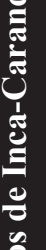 & 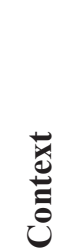 & 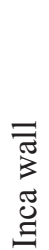 & 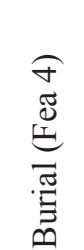 & 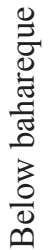 & 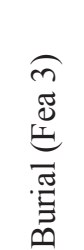 & 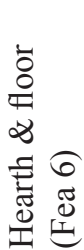 \\
\hline $\begin{array}{l}0 \\
0 \\
\dot{0} \\
\dot{\sigma} \\
\frac{\sigma}{0} \\
\frac{\sigma}{\sigma}\end{array}$ & $\begin{array}{l}\text { \# } \\
\text { 号 } \\
\text { ב }\end{array}$ & $\begin{array}{l}\stackrel{0}{0} \\
\hat{N} \\
\infty \\
\stackrel{1}{1} \\
\frac{\sigma}{0} \\
\infty \\
\infty\end{array}$ & 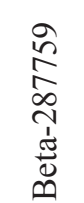 & 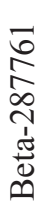 & $\begin{array}{l}n \\
\hat{\infty} \\
\infty \\
\infty \\
\dot{1} \\
\dot{1}\end{array}$ & $\begin{array}{l}0 \\
n \\
\infty \\
\infty \\
\infty \\
1 \\
\sum\end{array}$ \\
\hline
\end{tabular}




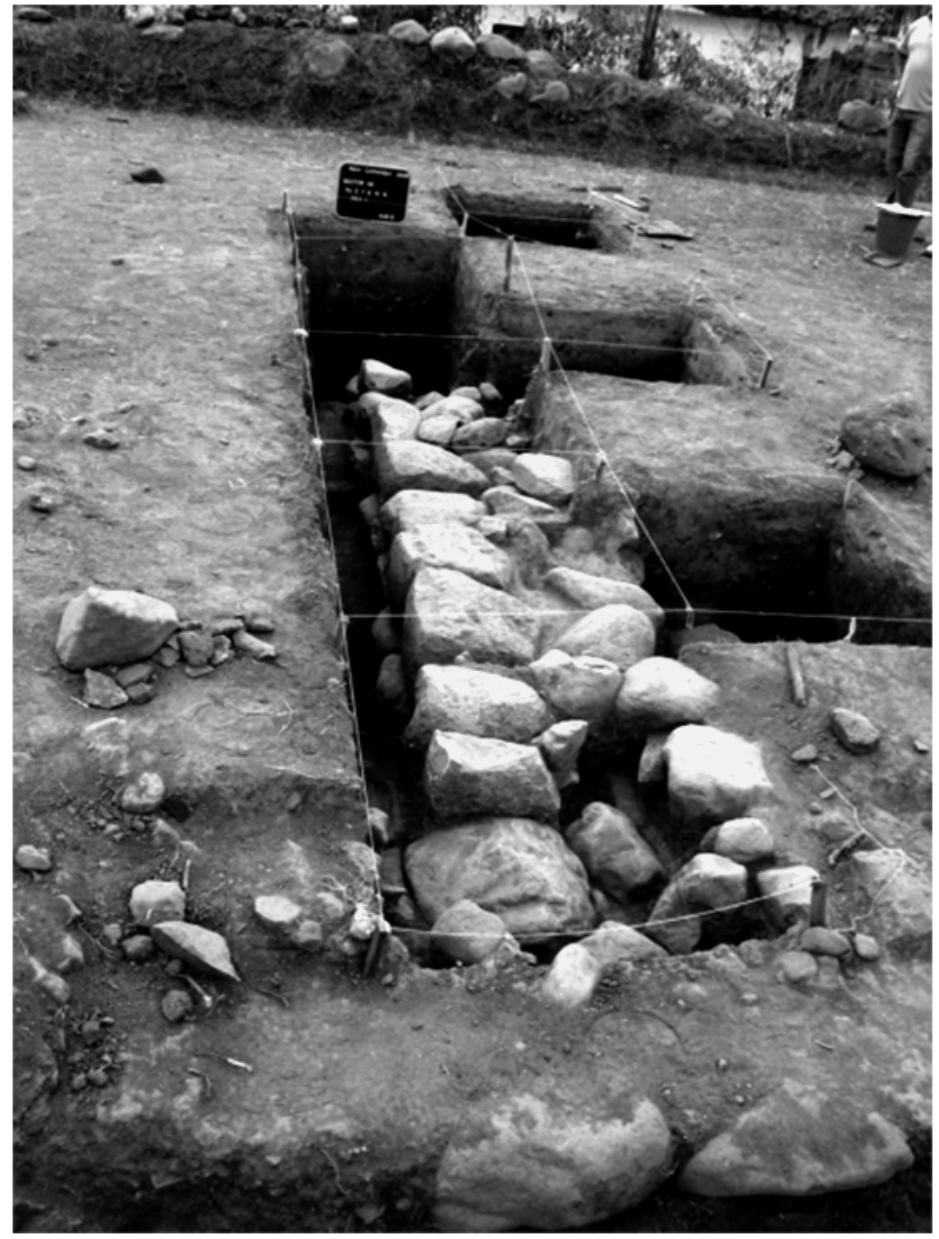

Foto 4. El MURo INCA ORIENTAdo NORTE-SUR (RASGo 1) DESCUBiERTO EN EL LADO NORTE DEL TEMPLO SEMISUBTERRÁNEO. LOS MUROS SON DE DOS HILERAS EN ALTURA Y COMPUESTOS DE PIEDRAS CON CARAS EXTERIORES TRABaJAdas y CON UN NÚCleO de RELleno. Foto POR TAMARA Bray.

\section{Arquitectura hidráulica Inca-Caranqui}

El rasgo arquitectónico más impresionante del sitio es la estructura semi-subterránea que hemos interpretado como un templo de agua. El piso del rasgo mide 16 metros N/S x 10 metros E/O (ver foto 3). Información de GPR y la estratigrafía indica que los Incas nivelaron y prepararon a propósito la cavidad excavada para recibir el primero de los dos pisos de piedra. El piso inferior está compuesto de piedras cuadrangulares que miden, en promedio, $25-30 \mathrm{~cm} 2$. El piso superior muestra un estilo diferente de pavimentación que involucra piedras más pequeñas y de forma poligonal, las mismas que encajan de manera irregular en un patrón curvilíneo. La materia prima para ambos pisos, así como para las otras estructuras Inca en el sitio, consiste de andesita porfídica local que contiene porcentajes variantes de plagioclasas, piroxena y anfíbol. Esta roca es relativamente suave (6 a 7 en la escala de Mohs) y probablemente deriva de los flujos piro-clásticos de las erupciones del Imbabura (Andrés Gorki Ruiz, comunicación personal; 
Bray y Echeverria, 2009: 63). Sin embargo, las piedras del piso superior, además de ser más pequeñas en tamaño y de forma irregular, son más vesiculares que aquellas del nivel inferior, es decir que el primer piso fue construido de roca más dura que el segundo.

El flujo de agua tanto desde y hacia esta estructura semi-subterránea fue clave para cualquier actividad ritual que se ejecutara en ella así como para el probable movimiento humano dentro y fuera de la estructura por medio de la serie de entradas escalonadas que se ubican en las cuatro esquinas. El agua fue claramente dirigida a este rasgo ceremonial desde el sur y entraba por medio de una serie de chorreras en el lado sur y un canal principal de piedra que corría a lo largo del lado sud-este de la estructura (figura 4; ver Romero y Bray, 2014). Según la información recogida por Echeverría (2009) del señor Luis Molina de 70 años de edad, oriundo de San Gabriel, Carchi, quien vive 40 años en Caranqui y trabaja de plomero y haciendo adobes, hasta hace unos 10 años había un canal de agua que cruzaba por el terreno al sur de Miguel Dávila, y salía sesgo a la esquina sureste del "baño del Inka."

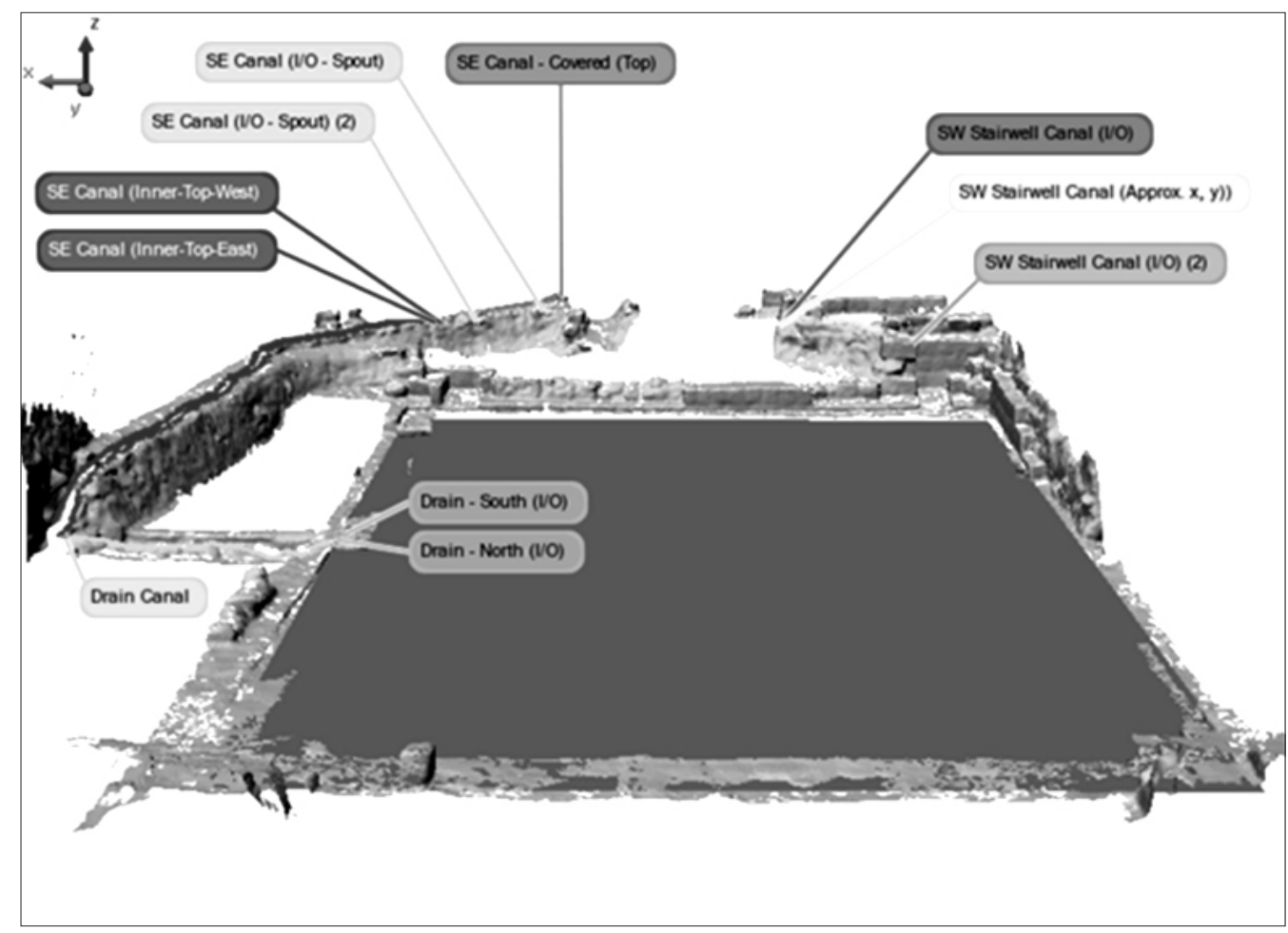

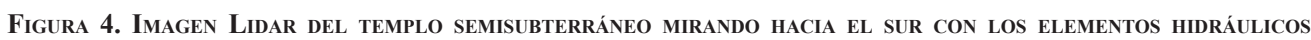
CONSISTIENDO DE CANALES, CHORRERAS Y DRENAJES INDICAdO EN VARIAS COLORES. IMAGEN ELABORADO POR Boleslo E. Romero.

Cualquier agua que se retuviera en el piso del templo pudo haber drenado hacia la quebrada que existió al este de este sector mediante dos agujeros tallados de drenaje que se unían con un canal orientado de este-oeste y que se ubicaba en el punto medio del borde este de la piscina (foto 5a). Dos tapones de piedra se encontraron in situ en estos agujeros de drenaje cuando la estructura fue expuesta inicialmente (foto 5b). En el lado opuesto al canal de salida y de los agujeros de drenaje, hay evidencia de dos terrazas bajas que fueron cortadas, rellenadas y fachadas con piedra trabajada. Estos pueden representar espacios para observar, corredores de tránsito o haber servido para otro propósito. En las esquinas nor-oeste y sud-este del templo semi-subterráneo tenemos evidencia de dos cuartos de pequeño tamaño. 
Nuestra interpretación de esta única estructura ligada al agua es aún tentativa, dado que no hemos terminado de procesar los datos arquitectónicos e hidráulicos. Es claro, sin embargo, en base solamente a su morfología, que se trata de algo nuevo dentro del repertorio arquitectónico Inca. Mientras mantiene unas ciertas similitudes a otras estructuras relacionadas con el agua que se han encontrado en otros sitios asociados con Huayna Capac, especialmente sus aposentos en Quispiguanca y las habitaciones para caza de Cocha Sontor en el valle de Urubamba (Niles, 1999), no existe evidencia de sitios Inca que tengan una estructura tipo baño con "entradas" de esta naturaleza. El tamaño de esta estructura y el aparente interés en la manipulación de los flujos - tanto humanos como de agua — a través del espacio semi-subterráneo sugieren una nueva preocupación de parte del estado imperial, potencialmente relacionado con diferentes estrategias para hacer sitios y el tomar la nueva frontera norte así como condiciones específicas de conquista y control durante la fase tardía de la expansión imperial. El tamaño inusual y la configuración de la piscina en Caranqui apuntan a su posible uso ritual por un gran número de personas, lo que a su vez sugiere la posibilidad de representaciones o actividades de una naturaleza más pública. Este rasgo también habla de un nuevo interés imperial en el control y captura de agua a gran escala, que puede reflejar estrategias cambiantes de política en las fases tardías del gobierno Inca (ver también Bray, 2013).

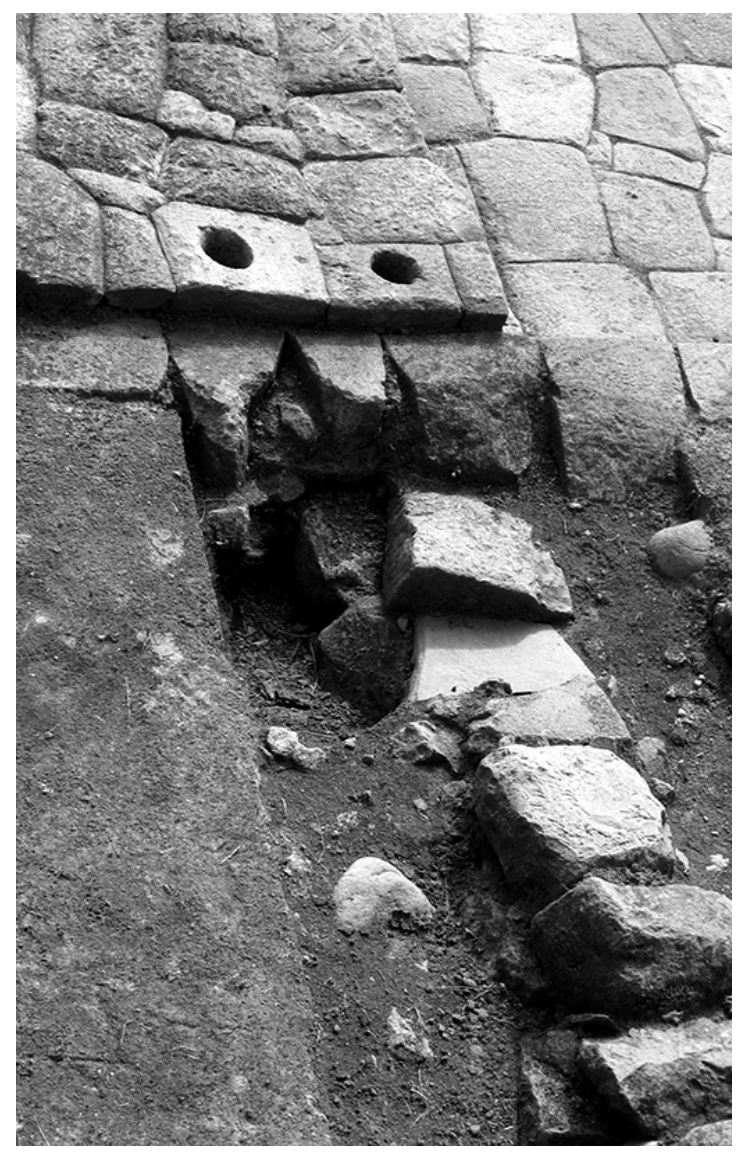

Foto 5, Canal de salida y las dos piedras con agujeros tallados de dRenaje al filo este-Central de la PLAZa SEMI-HUNDIDA. (A) LAS PIEDRAS CON AGUJEROS TALladoS Y EL CANAL DE SALIDA ASOCIADA; (B) LAS DOS PIEDRAS tallados con las tapas cónicas descubiertas in Situ. Fotos por Tamara Bray y José Echeverría. 
Los últimos elementos arquitectónicos a mencionarse aquí son la serie de canales hechos de piedra que servían al núcleo elite del sitio y que orquestaban el flujo de agua a través de él. La alimentación para este sistema de canales probablemente fue el flujo de agua asociado a la quebrada Negrete (de aproximadamente ocho metros de ancho) que previamente recorría el borde de la calle Huiracocha y que pudo haber formado el límite este del centro elite del sitio. Esta quebrada, que fue utilizada para tubería de alcantarillado por la municipalidad en 2007, ya no es visible, aunque aparece en un mapa del sector de 1998 (Tobar, 1998) y es recordada por los residentes de la localidad. Dentro del núcleo elite del sitio tenemos dos tipos distintos de canales (foto 6). El primero de estos tipos es tanto revestido como cubierto por piedras ligeramente modificadas; el segundo consiste de segmentos individuales de piedra tallada, de $35-70 \mathrm{~cm}$. de largo, con canales ranurados, los mismos que se arreglan de tal manera que forman un único cauce. Estas piedras cortadas varían en tamaño desde $27-42 \mathrm{~cm}$. de largo por $20-30 \mathrm{~cm}$. de ancho, con los canales ranurados de entre $6-7 \mathrm{~cm}$. de profundidad y $8-16 \mathrm{~cm}$. de ancho. Actualmente estamos investigando posibles explicaciones para las diferencias de estilo en tanto pueden relacionarse con distintas funciones, status, o distintos episodios constructivos.

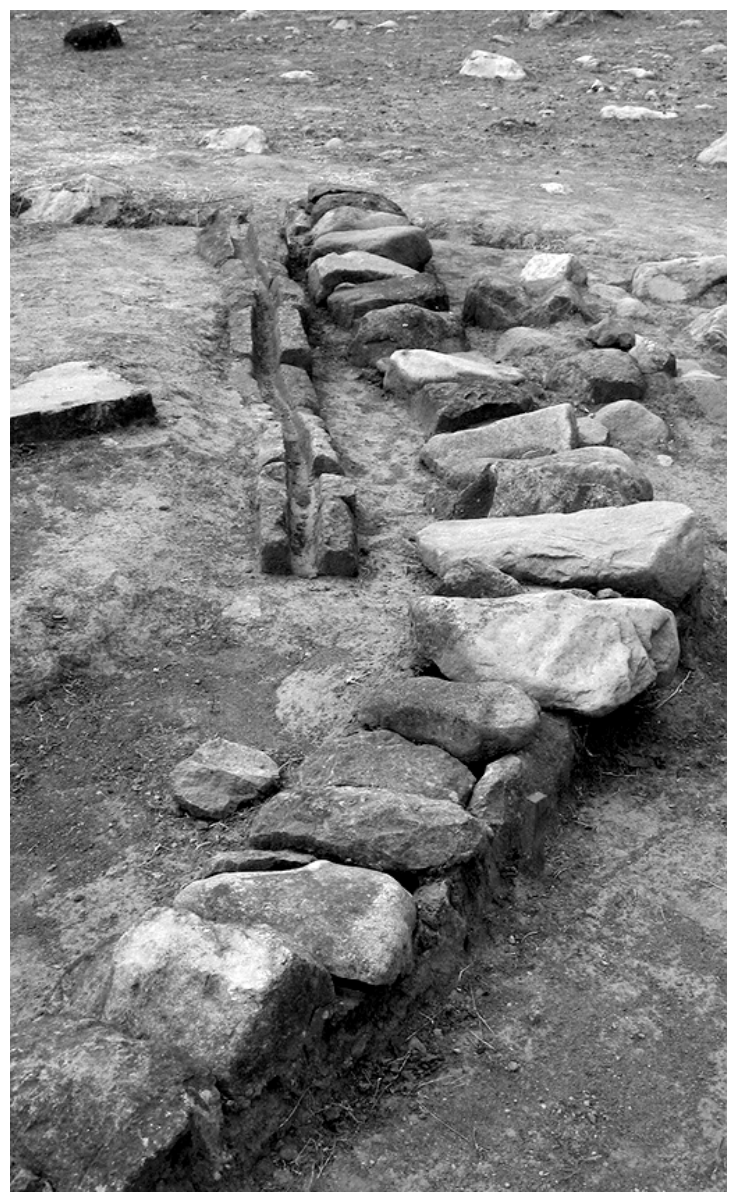

Foto 6. Dos tipos diferentes de CANAles en InCa-CARANQui, uno a LAdo DE OTRo EN EL SECTOR NORTE-CENTRAL

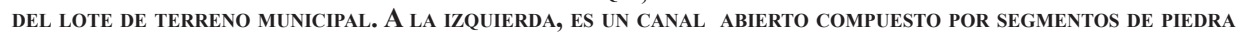
TALLADOS INDIVIDUALMENTE CON CANAL INTERIOR UNIDOS EN SUS EXTREMOS. A LA DERECHA, EN FORMA PARALELA, un CANAL CON CUbierta TAMbiÉn DE PIEDRas. Foto POR TAMARa Bray. 


\section{Cronología del sitio}

Con respecto a la cronología del sitio, tenemos un total de cinco fechas radio-carbónicas que están asociadas a los rasgos excavados Inca-Caranqui. Estas revelan que estamos tratando con ocupaciones radicalmente discontinuas. La muestra de carbón asociada con el muro Inca al norte de la plaza rindió una fecha de 450 +/- 40 BP. Como se indica en la tabla 1, los rangos de las fechas calibradas ${ }^{6}$ sugieren un rango temporal algo temprano para la actividad constructiva Inca, respecto a los datos históricos. Pero como siempre, el rango de error involucrado con la datación con radio-carbono, aunque sea mínima, crea un problema cuando nos interesan eventos históricos que ocurren en el transcurso de pocas décadas - y una sola fecha radio-carbónica no puede, por supuesto, ser tomada como algo más que un dato interesante en base al cual especular.

Mientras que la datación absoluta de la presencia Inca en Caranqui no puede ser resuelta al momento, es poco probable que la actividad constructiva imperial haya comenzado aquí previo a las guerras Caranqui-de otra manera, sería difícil imaginarse por que Yaguarcocha y sus alrededores han sido vistos como sitios de refugio por la población local. Habiendo dicho esto, la única fecha de C14 asociada al Inca en Caranqui se alinea bien con el corpus de fechas radio-carbónicas de otros sitios Inca en el Ecuador (Bray, 2014). Aún cuando ninguna de estas muestras puede tomarse individualmente como suficientemente precisas para apuntar a un evento histórico específico, el corpus general de fechas absolutas para la sierra norte, así como para otros sitios provinciales a los largo de los Andes, han empezado a expandir la cronología tradicional, comprimida de la expansión imperial basada en las crónicas (Adamska y Michczynski, 1996; Bauer, 1992; Ogburn, 2012).

Las otras cuatro fechas obtenidas para el sitio están relacionadas con los entierros y con estratos más bajos, ricos en depósitos orgánicos, bajo los 50-100 cm. de superficie. Estas fueron una sorpresa en tanto que se agrupan estrechamente entre 2000-2100 años BP cuando estábamos esperando fechas más recientes, ligadas a las ocupaciones Caranqui protohistóricas o Inca (ver tabla 1). Esta ocupación temprana fue claramente sustancial. Mientas que los enterramientos asociados no son particularmente ricos, el mejor conservado es aquel de una mujer mayor, de aproximadamente 45 años de edad, que fue enterrada con una compotera agrandada, similar en términos de forma y tratamiento de superficie a la típica vajilla Caranqui de períodos más tardíos; con un collar de cuentas pequeñas de concha; un objeto de piedra pómez con ranura de función desconocida; y dos pequeños discos de oro doblados (foto 7). Si esta ocupación temprana pudo ser conocida por los Incas no es claro, aunque parece tanto por la estratigrafía y la relación horizontal entre la pared Inca y este entierro en particular que fue probable que existiera cierto conocimiento de parte de los cuzqueños de estar construyendo sobre o en un cementerio Caranqui (foto 8).
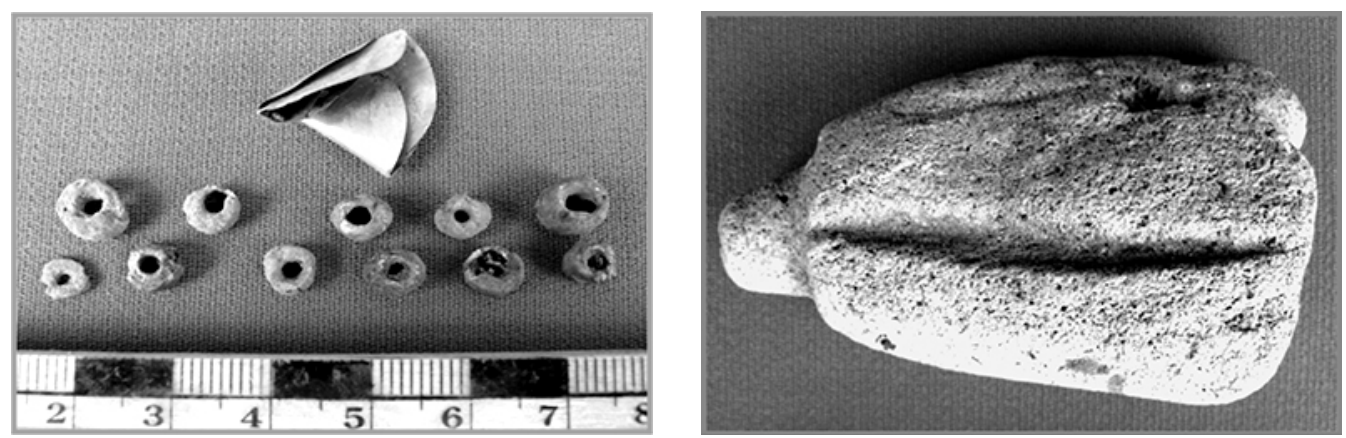

6 Las calibraciones en la tabla 1 están dadas usando tanto las curvas internacionales como del hemisferio sur, aunque da la ubicación de Caranqui a $40 \mathrm{~km}$. norte del ecuador, la curva internacional puede ser la más apropiada. Ver Ogburn (2012) para mayor discusión respecto a la calibración en los Andes. 


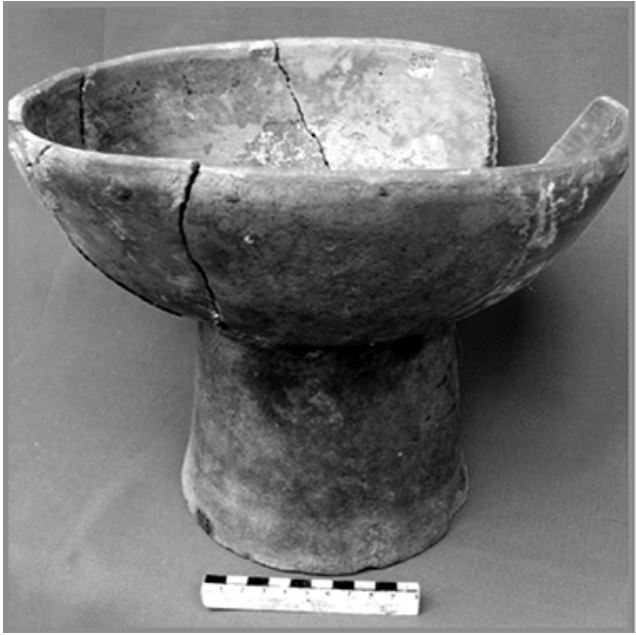

Foto 7. Artículos funerarios asociados CON El entierro (RASGo 3) DE UNA MUJER ADUlta (40 + AÑos), LOS RESTOS FUERON ENCONTRADOS EN UN POZO SIMPLE DE MEDIO METRO DE PROFUNDIDAD CORONADO POR UN PEQUEÑO MONTÓN DE PIEDRAS, SE UBICA INMEDIATAMENTE AL NORTE DEL ESPACIO CEREMONIAL SEMI-SUBTERRÁNEO, ADYACENTE AL LAdO ESTE DE UN MURO INCA (RASGO 2). (A) dOS DISCOS DE ORO DELGADOS (2,7 CM. DE Dí́METRO) DOBLADAS POR LA MITAD DOS VECES, LOCALIZADOS CERCA DEL LADO IZQUIERDO DE LA MANDÍBULA JUNTO CON CUENTAS DE CONCHA; (B) UN OBJETO DE PIEDRA PÓMEZ ACANALAdO Y CON UN EXTREMO A MANERA DE PEZÓN DE FUNCIÓN DESCONOCIDA ENCONTRADO CERCA DEL ESTERNÓN DEL INDIVIDUO (8,2 CM. DE LARGO Y ANCHO DE 4,5 CM. COMO MÁXIMO); (C) COMPOTERA DE GRAN TAMAÑO CON EL LABIO ROJO Y EL FONDO DESGASTADO, SITUADO CERCA DE LA CADERA DE LA persona (21 CM. DE altura; 27 CM dí́metro del borde). Fotos Tamara Bray.

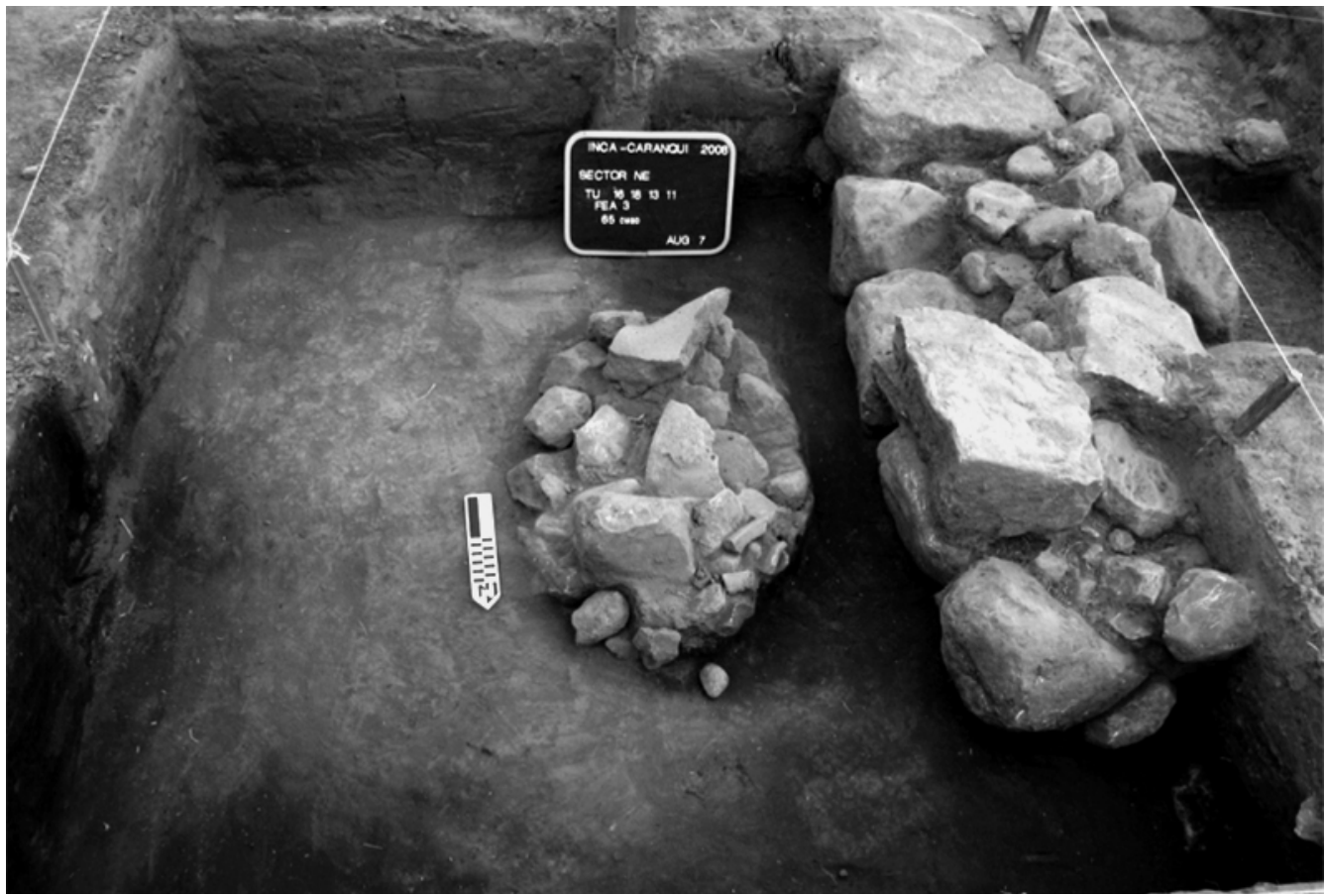

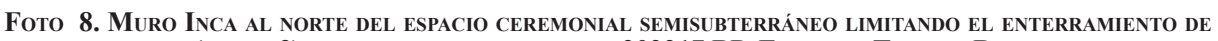

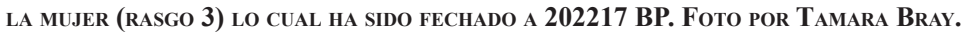




\section{Reflexiones Finales}

A manera de conclusiones de este reporte preliminar, reiteramos que una de las metas originales de nuestra investigación en el sitio Inca-Caranqui fue investigar el rol del ambiente construido como un elemento de la estrategia de dominación del estado Inca. Especialmente nos interesa como la arquitectura imperial Inca pudo haber funcionado para comunicar nuevos principios de orden socio-político, como pudo servir para reconfigurar las relaciones sociales, y como el énfasis arquitectónico puede haber cambiado en respuesta a las condiciones locales y a las necesidades cambiantes del Imperio durante la fase tardía o madura de su existencia.

La arquitectura única relacionada al agua que se ha documentado en Inca-Caranqui indica que la manipulación ritual de este elemento continua figurando prominentemente en el proceso de imperialización hacia el fin del imperio. Pero sugiere también que esta sustancia vital estaba siendo tratada en nuevas y muy diferentes maneras que presumiblemente tienen que ver con los imperativos cambiantes del Imperio. Esperamos que nuestros análisis sobre la organización hidráulica, arquitectónica y de artefactos aún en curso en el sitio Inca-Caranqui, en combinación con estudios comparativos más amplios, pueda en última instancia proveernos con una mayor percepción de la relación entre la materialidad del gobierno imperial y los principios ideológicos en los que se basa, así como en la manera en que cambian a lo largo del tiempo.

Con respecto a la información etnohistórica pertinente al sitio, creemos que los datos arqueológicos pueden ofrecer una resolución a los recuentos conflictivos sobre su fundación. El hecho de que el templo semi-subterráneo haya sido re-pavimentado en algún punto con un estilo diferente de albañilería junto con otra evidencia arquitectónica del sitio, sugiere que puede haber sido renovado para un nuevo o más elaborado propósito. Podemos especular que este evento de remodelación, ciertamente llevado a cabo en las estructuras pre-existentes, puede estar relacionado con las preparaciones de Atahualpa para formalmente recibir la insignia de gobierno luego de la muerte de su padre, Huayna Capac. Esta es una de las hipótesis que perseguimos mientras avanzamos en nuestros estudios.

\section{Agradecimientos}

Nuestra investigación en el sitio Inca-Caranqui ha sido apoyada por fondos del National Endowment for the Humanities, la Wenner-Gren Foundation, la National Geographic Society, Dumbarton Oaks, y Wayne State University. Sin el generoso auspicio de estas instituciones y agencias, nuestras investigaciones en el sitio no podrían haber avanzado. La finalización de este reporte fue hecha posible, en parte, con el apoyo del proyecto Prometeo de la Secretaría Nacional de Educación Superior, Ciencia y Tecnología (Senescyt) de la República del Ecuador; el GADM, Cantón Ibarra y la Universidad Técnica del Norte. Estamos así mismo en deuda con los habitantes de Caranqui y la vecina comuna San Clemente por su interés, apoyo y estímulo para nuestra investigación. Entre estos, quisiéramos reconocer especialmente al Dr. Gonzalo Checa, expresidente de la parroquia, la historiadora local Susana Aguirre, Don Tobías Flores, Arq. Pablo Cabascango y Sr. Miguel Chávez, a todo Caranqui, y a Alfonso y Martina Pupiales de San Clemente. Varios especialistas contribuyeron con su experiencia para nuestro proyecto, incluyendo al Dr. Larry Conyers, Denver University; Msc. Tamara Estupiñán; Dr. Andrés Gorki Ruiz, Escuela Politécnica Nacional; Dr. Cristobal Landázuri, PUCE; Dr. Rudy Larios, Copan Project; Dr. Leah Minc, Oregon State University; Sr. Boleslo Romero, University of California at Santa Barbara; Dr. Peter Stahl, University of Victoria; and Dr. Christian Wells, University of South Florida. Muchos otros contribuyeron en la excavación, procesamiento y análisis de los restos arqueológicos Inca-Caranqui. Entre ellos quisiéramos agradecer especialmente a Robert Arrunate, cuidador extraordinario del sitio y a su esposa Mariuxi Velásquez; a la arqueóloga de la Unidad de Protección del Patrimonio Cultural y Natural del cantón Ibarra Msc. Cristina Muñoz; y los estudiantes de arqueología Daniela Balanzátegui, Jon Brewster, Andrea DiMuzio, Pedro 
Fiallos, Fernando Flores, Kate Frederick, Krystal Hubbard, Amy Krull, Catherine Lara, Brian McCray, Julio Mena, María Patricia Ordoñez, Byron Ortiz, Brittney Tatchell, Francisco Sánchez, Josefina Vásquez, Kaitlin Yanchar, y Michelle Young. Finalmente, agradecemos especialmente a María Patricia Ordoñez por su traducción de este artículo a español.

\section{Bibliografía}

Adamska, Anna and Adam Michcznski, 1996, “Towards Radiocarbon Chronology for the Inca State”, en: Andes: Boletín de la Misión Arqueológica Andina 1, pp. 35-58.

Alcina Franch, José, 1981, "Fechas radiocarbónicas en la arqueología del Ecuador", en: Revista Española de Antropología Americana 11, pp. 95-101.

Aguilar, Gerónimo de, 1965 [1582], Relación fecha por mi, Fray Gerónimo de Aguilar, del orden de nuestra Señora de las Mercedes, Rendition de los cautivos, de la doctrina y pueblo de Caguasqui y Quilca, en: Marcos Jiménez de la Espada (Ed.), Relaciones Geográficas de Indias, tomo 2, ediciones Atlas, Madrid, pp. 245-247.

Athens, J. Stephen,2012, El Sitio Tola de la Hacienda Zuleta: Investigaciones 2010. Manuscript on file, National Institute of Cultural Patrimony, Quito.

2003, Inventory of Earthen Mound Sites, Northern Highland Ecuador. Manuscript on file, National Institute of Cultural Patrimony, Quito.

1992, "Ethnicity and Adaptation: The Late Period-Cara Occupation in Northern Highland Ecuador", en: Edward M. Schortman and Patricia A. Urban (Eds.), Resources, Power, and Interregional Interaction, Plenum Press, New York, pp. 193-219.

1980, El proceso evolutivo en las sociedades complejas y la ocupación del Período Tardío Cara en los Andes Septentrionales del Ecuador. Colección Pendoneros, Instituto Otavaleño de Antropología, Otavalo.

1978, Evolutionary Process in Complex Societies and the Late Period-Cara Occupation of Northern Highland Ecuador. Ph.D. Dissertation, University of New Mexico. University Microfilms, Ann Arbor.

Atienza, Lope de, 1931 [1575?], "Compendio histórica del estado de los indios del Perú", en: Jacinto Jijón y Caamaño (Ed.), La religión del imperio de los Incas, Escuela Tipográfica Salesiana, Quito.

Bauer, Brian, 1992, The Development of the Inca State. University of Texas Press, Austin.

Bedoya Maruri, Ángel, 1979, "Ruinas arqueológicas en Caranqui", en: Boletín Histórico 9 y 10, Dirección de Historia y Geografía del Estado Mayor Conjunto de las FF.AA. Quito, pp. 152-157.

Betanzos, Juan de, 1996 [1551-1557], Narrative of the Incas. Translated and edited by Roland Hamilton and Dana Buchanan. University of Texas Press, Austin.

Borchart de Moreno, Christiana, 2007, El Corregimiento de Otavalo: Territorio, Población y Producción Textil (1535-1808). Centro de Investigaciones, Universidad de Otavalo, Otavalo.

Borja, Antonio, 1965 [1591], "Relación en suma de la doctrina e beneficio de Pimampiro y de las cosas notables que en ella hay, de la cual es beneficiado el P. Antonio Borja", en: Marcos Jiménez de la Espada (Ed.), Relaciones Geográficas de Indias, edited by, t. 184, Atlas, Madrid, pp. 248-253.

Bray, Tamara L. 2014, "At the End of Empire: Imperial Advances on the Northern Frontier" en: Izumi Shimada (Ed.), The Inca Empire: A Multidisciplinary Approach to a Holistic Vision, University of Texas Press, Austin.

2013, "Water, ritual and power in the Inca Empire", en: Latin American Antiquity 24 (2), pp.164-190.

2008, "Chiefdoms of the Ecuadorian highlands", en: Helaine Silverman and William H. Isbell (Eds.), Handbook of South American Archaeology, Kluwer Academic Publishers, New York, pp.527-543.

2005 "Archaeological Investigations in Northern Highland Ecuador: The Pimampiro District as a Multi-Ethnic Locale", en: Journal of Field Archaeology 30(2), pp.119-141.

1991 The Effects of Inca Imperialism on the Northern Frontier. Ph.D. dissertation, State University of New York, Binghamton. University Microfilms, Ann Arbor.

Bray, Tamara L. and José Echeverría, 2011, Informe Anual para el Proyecto "La Arquitectura de Poder: Investigaciones al Sitio Imperial Tardio de Inca-Caranqui, Ibarra, Ecuador, Fase 3, (2010)." Manuscript on file, National Institute of Cultural Patrimony, Quito, Ecuador.

2010, Informe Anual para el Proyecto "La Arquitectura de Poder: Investigaciones al Sitio Imperial Tardio de Inca-Caranqui, Ibarra, Ecuador, Fase 2 (2009)," Manuscript on file, National Institute of Cultural Patrimony, Quito, Ecuador. 
2009, Saving the Palace of Atahualpa: The Late Imperial Site of Inca-Caranqui, Imbabura Province, Northern Highland Ecuador. Published on-line at Dumbarton Oaks, http://doaks.org/research/pre_columbian/doaks_ pco_project_grant_report_2008.html, accessed April 20, 2014.

Cabello de Balboa, Miguel, 1951, Miscelánea Antártica. Universidad Nacional Mayero de San Marcos, Lima. [1586].

Caillavet, Chantal, 2000, Los cacicazgos prehispánicos del norte del Ecuador: Asentamientos y distribución demográfica. In Etnias del Norte: Etnohistoria e Historia de Ecuador, edited by Chantal Caillavet, pp. 139158. Abya-yala Press, Quito.

1988, "Les chefferies prehispaniques du nord de l'equateur: formes d'habitat et organisation territoriale", en: Bulletin de l'Institut Francais d'Etudes Andines 27(2), pp. 41-59.

1985, "La adaptación de la dominación incaica a las sociedades autóctonas de la frontera septentrional del imperio (territorio Otavalo-Ecuador)", en: Revista Andina 3 (2), pp. 403-423.

1983, Toponimia histórica, arqueología, y formas prehispánicas de agricultura en la región de Otavalo, Ecuador, en: Bulletin de l'Institut Francais d'Etudes Andines, 12(3-4), pp.1-21.

1981, "Etnohistoria ecuatoriana: nuevos datos sobre el Otavalo prehispánico", en: Cultura: Revista del Banco Central 11, pp.109-127.

Chacón, Rosalba and Fernando Mejia, 2006, Proyecto arqueológico "Pucara de Rumicucho, excavación y restauración del Pucara de Rumichuco, primera terraza. Manuscript on file, FONSAL, Quito.

Cieza de Leon, Pedro de, 1995 [1553], Crónica del Perú, primera parte. Edited by Franklin Pease. PUCP Fondo Editorial, Lima.

Connell, Sam, 2006-07, Datación radiocarbónica. In Informe preliminar del proyecto arqueológico Pambamarca, 2006 \& 2007, Manuscript on file, Instituto Nacional de Patrimonio Cultural, Quito, pp. 88-90.

Conyers, Lawrence, n.d. Preliminary Field Report on GPR Mapping at Inca-Caranqui, Northern Highland Ecuador, 2008. Manuscript on file, Department of Anthropology, Wayne State University.

Coronel, Rosario, 1991, El valle sangriento: de los indígenas de la coca y el algodón a la hacienda Cañera Jesuita, 1580-1700. Abya-Yala Press, Quito.

Costales, Alfredo and Dolores Costales Peñaherrera, 2002, Huambracuna: la epopeya de Yahuarcocha. Abyayala Press, Quito.

Cruz, Marco, 2011, Descubrimiento precolombino en el Chimborazo. Bitácora Ecuador Magazine, June-July, 19, pp. 20-27.

Echeverría, José, 2009, Prospección arqueológica en el predio del señor Amable Isaías Torres Clerque y otros, ubicado en la avenida Atahualpa y calle La Huaca, parroquia Caranqui, Ibarra, Imbabura. INPC, Quito.

2006-07, Proyecto "alternativas turísticas de Caranqui: investigación y puesta en valor de los vestigios arquitectónicos del palacio de Atahualpa. Fase I. Primer informe. Fonsalci, Ibarra.

Echeverría, José and Tamara L. Bray, n.d. Las Tolas Pérdidas de Caranqui. Manuscrito en preparación.

Echeverría, José, José Berenguer, and María Victoria Uribe, 1995, "Prospecciones en el valle del ChotaMira (Carchi-Imbabura)", en: José Echeverría and María Victoria Uribe (Ed.) Área Septentrional Andina Norte: Arqueología y Etnohistoria, Colección Pendoneros, Ediciones Abya-Yala, Instituto Otavaleño de Antropología, Otavalo, Ecuador, pp. 45-148.

Espinosa, Waldemar, 1983, Los Caranquis y los Cayambes: siglos XV-XVI y el testimonio de la etnohistoria. Colección Pendoneros, Instituto Otavaleño de Antropología, Otavalo, Ecuador.

Estupiñán, Tamara, 2011, "Los Sigchos, el último refugio de los incas quiteños. Una propuesta preliminar," Bulletin de l'Institut Français d'Études Andines 40 (1), pp. 191-204.

Gondard, Pierre and Freddy López, 1983, Inventario arqueológico preliminar de los andes septentrionales del Ecuador. MAG, PRONAREG, and ORSTOM, Quito.

González, Ana Maria, Sam Connell, and Chad Gifford, 2009, Preliminary Report for the Pambamarca Archaeology Project 2006 \& 2007. Manuscript on file at the National Institute of Cultural Patrimony, Quito, Ecuador.

Jijón y Caamaño, Jacinto,1920, "Nueva contribución al conocimiento de los aborígenes de la provincia de Imbabura", en: Boletín de la Sociedad Ecuatoriana de Estudios Históricos Americanos 4 (10):1-120, 4 (11), pp. 183-244.

1914, Contribución al conocimiento de los aborígenes de la provincia de Imbabura en la república del Ecuador. Blas y Cía., Madrid.

Krull, Amy, 2014, Smashed: Ceremonial Intoxicants \& Intentional Tool Destruction. MA Thesis, Department of Anthropology, Wayne State University, Detroit, Michigan. 
Kunter, Kari, 1981, "La serie de esqueletos humanos de Cochasquí y de otras regiones del Ecuador", en: Udo Oberem (Ed.), Cochasqui: Estudios Arqueológicos, Colección Pendoneros, Instituto Otavaleño de Antropología, Otavalo, Ecuador, pp. 171-218.

Landázuri, Cristóbal, 1990, "Pueblos indígenas de los valles interandinos: el caso de Pimampiro, siglo XVI", en: Quitumbe 7, pp.11-35.

Larrain, Horacio, 1980, Demografia y asentamientos indígenas en la sierra norte del Ecuador en el siglo XVI. Instituto Otavaleño de Antropología, Otavalo, Ecuador.

Lippi, Ronald and Alejandra Gudiño, 2010, "Inkas and Yumbos at Palmitopamba in Northwestern Ecuador", in: Michael Malpass and Sonia Alconini (Eds.), Distant Provinces in the Inka Empire, Iowa University Press, Iowa City, pp. 260-278.

Meyers, Albert, 1981, “Análisis de la cerámica de Cochasqui”, in: Udo Oberem (Ed.), Cochasquí: estudios arqueológicos, Colección Pendoneros, Instituto Otavaleño de Antropología, Otavalo, Ecuador, pp. 219-285.

Minc, Leah, Kaitlin Yanchar, Tamara L. Bray, and José Echeverría, 2014, "Potting Clays and Ceramic Provenance in Northern Highland Ecuador", in: Guillermo de la Fuente and Emily Stovel (Eds.), Avances en la Arqueometría Cerámica en Latinoamérica, British Archaeological Reports International, Oxford.

Montesinos, Fernando de, 1957 [1644], "Memorias Antiguas Historiales y Políticas del Perú", en: Revista del Museo e Instituto Arqueológico 16-17, Lima, pp.1-114.

Moreno, Segundo, 1988, "Formaciones políticas tribales y señoríos étnicos", en: Enrique Ayala (ed.), Nueva Historia del Ecuador, Vol. 2, Corporación Editora Nacional, Quito, pp. 10-134.

Niles, Susan,1999, The Shape of Inca History. University of Iowa Press, Iowa City.

1987, "Niched Walls in Inca Design", en: Journal of the Society of Architectural Historians 46, pp. 277-285.

Oberem, Udo,1981, Cochasquí: estudios arqueológicos. Colección Pendoneros, Instituto Otavaleño de Antropología, Otavalo, Ecuador.

1969, La fortaleza de montaña de Quitoloma, en: Boletín de la Academia Nacional de Historia 114, pp.195-204.

Ogburn, Dennis E., Samuel V. Connell, and Chad H. Gifford, 2009, "Provisioning of the Inka Army in Wartime: Obsidian Procurement in Pambamarca, Ecuador", in: Journal of Archaeological Science 36, pp.740-751.

Osborn, Alan and J. Stephen Athens, 1974, Prehistoric Earth Mounds in the Highlands of Ecuador: A Preliminary Report. Manuscript on file at the Otavaleño Institute of Anthropology, Otavalo, Ecuador.

Oviedo y Valdez, Gonzalo Fernández de, 1851-1855 [1534], La historia general de las Indias. Real Academia de la Historia, Tomo IV. Madrid y el Banco Central del Ecuador, Quito.

Pazmiño, Estanislao, 2009, Informe final del proyecto arqueológico Huataviro. Manuscript on file at the Instituto Nacional de Patrimonio Cultural, Quito.

Rodríguez, Byron, 2011, El Chimborazo revela ruinas prehispánicas. El Comercio, Culture Section, 5/18/2011, http://www.elcomercio.com/cultura/Chimborazo-revela-ruinas-prehispanicas_0_468553199.html

Romero, Boleslo E. and Tamara L. Bray, 2014, Analytical Applications of Fine-scale Terrestrial Lidar at the Site of Inca-Caranqui, Ecuador. World Archaeology 46, pp. 25-42.

Rowe, John H., 2008, A Question of Time: Juan de Betanzos and the Narrative of the Incas. Nawpa Pacha 29, pp. 155-162.

Salomon, Frank, 1986 Native Lords of Quito in the Age of the Incas. Cambridge University Press, Cambridge.

1978, Pochteca and Mindalá: A Comparison of Long-distance Traders in Ecuador and Mesoamérica. Journal of Steward Anthropology 9 (1-2), pp. 231-247.

Salomon, Frank L. and Sue E. Grosboll, 1986, "Names and People in Incaic Quito: Retrieving Undocumented Historic Processes through Anthroponymy and Statistics", in: American Anthropologist 88(2), pp. 387-399.

Tobar Subía, Cristóbal, 1985 [1929], Monografía de Ibarra. Centro de Ediciones Culturales de Imbabura, Ibarra.

Tobar A., Oswaldo, 1998, Prospección sistemática en el sector este de la calle La Huaca, Caranqui, Imbabura. Ilustre Municipio de Ibarra. Unidad de Proyectos, Mayo 1998.

Wernke, Steven A., 2007, “Analogy or Erasure?: Dialectics of Religious Transformation in the Early Doctrinas of the Colca Valley, Peru”, en: International Journal of Historical Archaeology 11(2), pp.152-182.

Xerex, Francisco de, 1985, Verdadera relación de la conquista del Perú. [1534]. Edited by Concepción Bravo. Crónicas de América, 14. Historia 16, Madrid.

Yanchar, Kaitlin, 2013, Degree and Scale of Interactions among Chiefdoms during the Pre-Hispanic Late Period in Northern Highland. Master's Thesis, Oregon State University, Eugene, OR.

Yépez, Alden, 2013, Excavaciones en dos sitios arqueológicos del volcán Chimborazo (Parroquia San Juan, provincia Chimborazo). Manuscript on file at the National Institute of Cultural Patrimony, Quito, Ecuador. 